\title{
Thermodynamics cycle analysis and numerical modeling of thermoelastic cooling systems
}

\author{
Suxin Qian, Jiazhen Ling, Yunho Hwang*, Reinhard Radermacher, Ichiro Takeuchi \\ Center for Environmental Energy Engineering, Department of Mechanical Engineering, \\ University of Maryland, 4164 Glenn L. Martin Hall Bldg., College Park, MD 20742, USA \\ *Corresponding Author \\ Tel: (+1) 301-405-5247, Fax: (+1) 301-405-2025, Email: yhhwang@umd.edu
}

\begin{abstract}
To avoid global warming potential gases emission from vapor compression air-conditioners and water chillers, alternative cooling technologies have recently garnered more and more attentions. Thermoelastic cooling is among one of the alternative candidates, and have demonstrated promising performance improvement potential on the material level. However, a thermoelastic cooling system integrated with heat transfer fluid loops have not been studied yet. This paper intends to bridge such a gap by introducing the single-stage cycle design options at the beginning. An analytical coefficient of performance (COP) equation was then derived for one of the options using reverse Brayton cycle design. The equation provides physical insights on how the system performance behaves under different conditions. The performance of the same thermoelastic cooling cycle using NiTi alloy was then evaluated based on a dynamic model developed in this study. It was found that the system COP was 1.7 for a baseline case considering both driving motor and parasitic pump power consumptions, while COP ranged from 5.2 to 7.7 when estimated with future improvements.
\end{abstract}

Key words: shape memory alloy, elastocaloric, efficiency, nitinol, solid-state cooling 


\section{Nomenclature}

\section{Symbols}

A

$\mathrm{Bi}$

COP

$c_{p}$

D

e

$\dot{e}$

F

GWP

g',

HR

HTF

$\Delta h$

$h$

ID

K

$k$

$L$

$m$

$\dot{m}$

$O D$

$Q$

$\dot{Q}$ material constant related to hysteresis energy $\left[\mathrm{J} \cdot \mathrm{g}^{-1}\right]$

Biot number

coefficient of performance

specific heat $\left[\mathrm{J} \cdot \mathrm{g}^{-1} \cdot \mathrm{K}^{-1}\right]$

mechanical efficiency loss factor

strain

strain change rate $\left[\mathrm{s}^{-1}\right]$

cyclic loss factor

global warming potential

generation term in energy equation $\left[\mathrm{W} \cdot \mathrm{m}^{-3}\right]$

heat recovery

heat transfer fluid

latent heat $\left[{\left.\mathrm{J} \cdot \mathrm{g}^{-1}\right]}^{-1}\right.$

heat transfer coefficient $\left[\mathrm{W} \cdot \mathrm{m}^{-2} \cdot \mathrm{K}^{-1}\right]$

internal diameter $[\mathrm{m}]$

material constant related to elasticity [MPa]

thermal conductivity $\left[\mathrm{W} \cdot \mathrm{m}^{-1} \cdot \mathrm{K}^{-1}\right]$

length [m]

mass [kg]

mass flow rate $\left[\mathrm{kg} \cdot \mathrm{s}^{-1}\right]$

outside diameter [m]

heat transferred [J]

capacity [W] 
capacity per unit mass $\left[\mathrm{J} \cdot \mathrm{g}^{-1}\right]$

RHS

right hand side

$s$

specific entropy $\left[\mathrm{J} \cdot \mathrm{g}^{-1} \cdot \mathrm{K}^{-1}\right]$

SMA

shape memory alloy

sec

second

$T$

$\Delta T_{\text {ad }}$

temperature $\left[{ }^{\circ} \mathrm{C}\right]$

adiabatic temperature span $[\mathrm{K}]$

$t$

time, or duration [sec]

$t^{*}$

$u$

$u^{*}$

$\dot{V}$

W

$\dot{W}$

w

VCC

$\alpha$

$\delta$

$\varepsilon$

$\sigma$

$\gamma$

$\eta$

$\kappa$

$\rho$

$\xi$

heat recovery coefficient

fluid mean velocity $\left[\mathrm{m} \cdot \mathrm{s}^{-1}\right]$

internal energy $\left[\mathrm{J} \cdot \mathrm{g}^{-1}\right]$

volumetric flow rate $\left[\mathrm{m}^{3} \cdot \mathrm{s}^{-1}\right]$

work [J]

work rate [W]

specific work $\left[\mathrm{J} \cdot \mathrm{g}^{-1}\right]$

vapor compression cycle

thermal diffusivity $\left[\mathrm{m}^{2} \cdot \mathrm{s}^{-1}\right]$

equivalent thickness [m]

effectiveness

stress [MPa]

non-dimensional latent heat

efficiency

thermal mass factor

density $\left[\mathrm{kg} \cdot \mathrm{m}^{-3}\right]$

martensite phase fraction 
martensite phase fraction change rate $\left[\mathrm{s}^{-1}\right]$

$\Delta$ material constant related to strain [-]

\section{Subscripts}

$\mathrm{ad}$

adiabatic

$\mathrm{AM}$

austenite to martensite

cyc cycle

$\mathrm{f}$

HT heat transfer

init initial

mat material

mot motor

MA martensite to austenite

rec recovery

s $\quad$ solid, solid heat exchanger or bed

sat saturation

trsm transmission

$+\quad$ loading

unloading

\section{Introduction}

Solid-state cooling technologies have been developed rapidly during the past few decades, including thermoelectric cooling (Sharp et al., 2006), magnetic cooling (Sarlah et al., 2006, Vasile and Muller, 2006, Zimm et al., 2006, Jacobs et al., 2014), electrocaloric cooling (Gu et al., 2013, Jia and Yu, 2012), thermoacoustic cooling (Reid et al., 1998, Swift et al., 1999, Yazaki et al., 2002), and most recently, thermoelastic cooling (Cui et al., 2012) (a.k.a. elastocaloric cooling). These solid-state cooling systems offer us alternatives to eliminate the emission of traditional 
high global warming potential (GWP) halogenated refrigerants used in the vapor compression cycle (VCC) systems. Compared with other alternative cooling methods, elastocaloric effect has a higher adiabatic temperature span, and therefore, it's possible to use a single stage cycle for typical air-conditioning and refrigeration applications. A more sophisticated ranking of solid-state materials also indicates that thermoelastic cooling materials are better than materials used for magnetic cooling (Qian et al., 2015) in terms of the material level performance. Therefore, from thermodynamics perspective, thermoelastic cooling can be easily applied to cooling systems as compared to its competitive technologies.

Thermoelastic cooling technology uses shape memory alloy (SMA), which is a group of metal alloys with significant elastocaloric effect. They can be used for power cycle, or applied reversely for thermoelastic cooling/heat pump cycles. In a power cycle, the driving potential is the temperature difference. While in a heat pump cycle, the applied stress induces the cooling and heating. In a cooling/heat pump cycle, the useful cooling/heating effect is the result of the associated latent heat released during the stress-induced martensitic phase change process, which makes the material transits between the martensite phase and austenite phase. As shown in Figure 1 (a), when the SMA is subjected to an external stress exceeding the phase change stress $\sigma_{\text {sat, }}$ austenite crystal starts to transform to martensite crystal, and meanwhile releases the latent heat to raise SMA's temperature at the same time. The cooling effect takes place when the external system stress is less than the $\sigma_{\text {sat }}$. As the stress decreases below the threshold, the material transits back to the "parent" state, the austenite state, and absorbs ambient heat. The SMA was famous for its unique mechanical property that it "remembers" an original "trained" shape, and can return to this pre-deformed shape upon heating above a transitional temperature. NiTi alloy and copper based alloys are most widely used as engineering functional materials for a variety of applications, including automotive, aerospace, mini actuators and sensors, biomedical, and orthopedic surgery (Jani et al., 2014). As the market of SMA grows, the cost of SMA reduces and it is now possible 
to use them for power generation and cooling/heat pump systems. Significant theoretical investigations for SMA heat engines have been carried out (Tong and Wayman, 1974, Ahler, 1975, Wayman and Tong, 1975, Delaey and Lepeleire, 1976, Cunningham and Ashbee, 1977, Ziolkowski, 1993), and a few prototypes were built (Sato et al., 2008, Kanada, 2008, Kaneko and Enomoto, 2009, Wakjira, 2001, Schiller, 2002) and simulated (Gil and Planell, 1999, Liu, 2004, Zhu et al., 2001a, Zhu et al., 2001b) in the past few decades. Existing SMA heat engines were either wire based wheels (Sato et al., 2008, Kanada, 2008, Kaneko and Enomoto, 2009, Wakjira, 2001), or spring-based on twin crank design (Schiller, 2002). A common design of SMA heat engine's heat source is a hot water bath, with an air cooled heat sink, therefore no complicated fluid lines are necessary. The simple design reduced the structural complexity, but left no room for applying heat regeneration between the cold SMA wire going into the hot water bath, and hot SMA wire leaving hot water bath, as indicated by Figure 2. Besides heat transfer, the work production is another essential part when it comes to evaluate the power generation efficiency. Early works on deriving the analytical efficiency relies on simple equilibrium stress-strain model (Tong and Wayman, 1974, Ahler, 1975, Wayman and Tong, 1975, Delaey and Lepeleire, 1976, Cunningham and Ashbee, 1977), where only a single stress-saturation temperature is needed and the computation of work is simple. Recent computation using analytical approach (Ziolkowski, 1993) used more sophisticated equilibrium stress-strain model to predict the corresponding efficiency. On the other hand, dynamic or quasi-steady state simulation using constitutive models and finite element or finite volume methods have been carried out in the past decade.

There are two concerns for the current literatures of SMA heat engines. First, most of the simple equilibrium analysis and the sophisticated dynamic model used the homogeneity assumption, which is in fact quite common in continuum mechanics and thermodynamics. However, applying such simplification to complicated shape memory alloy phase change could deviate from reality to a significant amount under some circumstances (Furst et al., 2012). To 
avoid complexity in calculation of the work needed to drive the cooling/heat pump cycle, experimental data were used to fit in a simple one-dimensional constitutive model, in order to evaluate the loading/unloading energy related to the coefficient of performance (COP) for this study. Such a decoupling of stress-strain relation from temperature allows for better understanding of the system level performance, rather than focusing on all the details of the material level performance. This practice will not lose much accuracy on the material level as long as real experimental loading/unloading data are applied.

Second, for simplicity consideration, neither the previous analytical approach nor the simulation in the literatures considered heat recovery/regeneration process to improve the efficiency. Besides, the control volume of the system they considered is only the SMA itself, excluding any heat transfer fluid loops and associated losses. It should be noted that the consideration of heat loss and thermal mass of fluid lines should not be neglected in cooling/heat pump systems. Those two factors becomes more significant when heat recovery loop is applied.

Apart from the two abovementioned concerns, the field of using SMA for cooling/heat pump cycle is completely new, and therefore a guideline on thermodynamic cycle analysis and modeling is necessary. Consequently, this paper intends to bridge the aforementioned gaps by analyzing some basic thermodynamic cycle options for a single-stage thermoelastic cooling/heat pump cycle at the beginning. The analytical $\mathrm{COP}$ analysis is then introduced, considering the significant effect of finite time heat transfer, cyclic losses, and heat recovery efficiency. A detailed dynamic model is developed to investigate the parametric effect of some design variables to the performance of the thermoelastic cooling system, and explore the potentials to improve the efficiency and where the limits are. 


\section{Basic thermodynamics cycles for thermoelastic cooling}

From thermodynamics point of view, the cooling/heat pump cycle is a reverse power cycle, because heat is pumped from a low temperature heat source (conditioned space, denoted by $T_{\mathrm{c}}$ ) to a high temperature heat sink (ambient, denoted by $T_{\mathrm{h}}$ ) by consuming power. For ideal thermoelastic material operated under reverse Carnot cycle, the cooling, heating and power input within one cycle is denoted in Eq. (1-3):

$$
\begin{aligned}
& q_{c}=T_{c} \Delta s \\
& q_{h}=T_{h} \Delta s \\
& w_{\text {net }}=q_{c}-q_{h}=-\left(T_{h}-T_{c}\right) \Delta s
\end{aligned}
$$

Here the entropy change associated with the martensitic phase change is a material constant, which is determined based on material composition. Practically, the power consumption within one cycle cannot be less than the one in the reversible case. The difference is caused by the hysteresis loss of the irreversibility during the crystal structure transformation from martensite to austenite and any friction in the transmission system and driving system. The associated latent and work deviated from ideal Carnot cycle, as listed in Eq. (4-9).

Generally speaking, a thermoelastic cooling/heat pump cycle can be achieved via two basic thermodynamic cycles: reverse Brayton cycle in Figure 3 and reverse Stirling cycle in Figure 4. The reverse Brayton cycle consists of two isentropic processes and two iso-stress processes. It starts from state 1 which the material is under unstressed austenite phase, and then stress is loaded to the material causing it moves to state 1' and martensitic phase change starts. The associated latent heat is then released from 1' to 2 adiabatically, causing the temperature to increase on the T-s diagram. Afterwards, the SMA temperature approaches the heat sink's temperature at $T_{\mathrm{h}}$, while the material itself is still fully stressed at martensite phase. Before fully unstressed, the SMA can be further cooled down to 4 by exchanging the sensible heat between one set of SMA 
material starting at state 3, and another set of SMA material just finished cooling the conditioned space at state 6. The heat exchanger process is so called a heat recovery process. Thermodynamics allows a $100 \%$ heat recovery efficiency, which means state 4 temperature could be the same as state 6 temperature. A detailed study on how to achieve high efficient heat recovery design is introduced in (Qian et al., 2015). A reverse adiabatic phase change process brings the SMA back to austenite from 4' to 5. This process is called unloading. During the rest of the cycle, the SMA remains unstressed. The cooling process to the conditioned space is from 5 to 6 , and reverse heat recovery process is from 6 back to 1 with the other set of SMA materials undergoes the process from 3 to 4 . The heat recovery process conserves energy, and therefore the heat rejected to sink should be equal to the summation of the heat absorbed from the conditioned space and the work needed to drive one cycle. It should be noted that the area underneath 1-1'-2 on the $\sigma-e$ (stress-strain) diagram is the loading work, and the area underneath $4-4$ ' -1 is the unloading work. If the system is designed properly, the unloading work can be fully used to compensate part of the loading work. Therefore, the area surrounded by the cycle on $\sigma-e$ diagram is corresponding to the net power input with $100 \%$ work recovery design.

The reverse Stirling cycle in Figure 4 contains two iso-stress heat transfer processes, and two isothermal phase change processes. The cycle begins at unstressed state 1, and is stressed to 1' before the phase change begins. Different from reverse Brayton cycle, the SMA material is cooled during the martensitic phase transformation process from $1^{\prime}$ to 2 , and therefore keeps a constant temperature while releasing the latent heat. The iso-stress heat recovery process from 2 to 3 is essentially the same as previously introduced. Afterwards, the unloading process from 3 to 4 via 3' takes place with the isothermal heating process, where the conditioned room air is cooled down by the system. The cycle concludes by the iso-stress heat recovery process.

Based on the simple physics based one-dimensional constitutive model (Muller and Xu, 1991, Fedelich and Zanzotto, 1991) and the method proposed for a thermoelastic power cycle 
(Ziolkowski, 1993), the ideal thermoelastic cooling cycle COP $\left(\mathrm{COP}_{\text {mat }}\right)$ using material model could be evaluated as follows. The difference between the Carnot COP and $\mathrm{COP}_{\text {mat }}$ is due to SMA hysteresis, which is also one of the intrinsic irreversibility of this technology.

$$
\begin{aligned}
& \sigma_{A M}(T)=\frac{\rho}{\Delta}\left(T \Delta s-\Delta u^{*}+A\right) \\
& \sigma_{M A}(T)=\frac{\rho}{\Delta}\left(T \Delta s-\Delta u^{*}-A\right)
\end{aligned}
$$

First, the phase change stress (or "saturation stress") at a given temperature is given by Eq. (4) (Ziolkowski, 1993). Note that the subscript "AM" refers to austenite to martensite, and vice versa. The difference between loading/unloading stresses at the same temperature is a direct measure of the hysteresis, represented by the material constant $A$. Here, the $A, \Delta, K$ and $\Delta u^{*}$ are four material constants used by the phenomenological model describing the phase change process, which are related to the elastocaloric effect and therefore could be derived from the measured data. Parameter $A$ is directly related to stress-strain curve hysteresis, i.e. irreversibility of the phase change process. Parameter $\Delta$ measures the stress variation during the phase change process. Parameter $K$ measures the elasticity of the SMA. $\Delta u^{*}$ is the internal energy change during the phase change process. More details in terms of these parameters and derivation of Eqs. (4-7) are available in the work by Ziokowski (1993). Also, for simplicity reason, specific entropy change $\Delta s$ was regarded as a material constant within the temperature range of interest. This approximation has enough accuracy for system level performance prediction, however, can be improved by more sophisticated methods to predict the dependency of $\Delta s$ on temperature.

$q_{c}\left(T_{c}\right)=\sigma_{M A}\left(T_{c}\right) \cdot \frac{\Delta}{\rho}+\Delta u^{*}=T_{c} \Delta s-A$

For reverse Stirling cycle, the amount of cooling per unit mass per cycle is in Eq. (5). 
$w_{+}\left(T_{h}\right)=\left[\sigma_{A M}\left(T_{h}\right) \cdot \Delta+\frac{\sigma_{A M}{ }^{2}\left(T_{h}\right)}{2 K}\right] / \rho$

The amount of loading energy per unit mass per cycle $w_{+}$is in Eq. (6).

$w_{-}\left(T_{c}, T_{h}\right)=\left[\sigma_{M A}\left(T_{c}\right) \cdot \Delta+\frac{\sigma_{A M}{ }^{2}\left(T_{h}\right)}{2 K}\right] / \rho$

The amount of unloading energy per unit mass per cycle $w_{-}$is in Eq. (7).

$\operatorname{COP}_{\text {mat }}=\frac{q_{c}\left(T_{c}\right)}{w_{+}\left(T_{h}\right)-w_{c}\left(T_{c}\right)}=\frac{T_{c} \Delta s-A}{\left(T_{h}-T_{c}\right) \Delta s+2 A}$

Therefore, the $\mathrm{COP}_{\text {mat }}$ for reverse Stirling cycle is equal to Eq. (8).

$C O P_{m a t}=\frac{q_{c}\left(T_{c}-\frac{\Delta T_{a d}}{2}\right)}{w_{+}\left(T_{h}+\frac{\Delta T_{a d}}{2}\right)-w_{c}\left(T_{c}-\frac{\Delta T_{a d}}{2}\right)}=\frac{\left(T_{c}-\frac{\Delta T_{a d}}{2}\right) \Delta s-A}{\left(T_{h}-T_{c}+\Delta T_{a d}\right) \Delta s+2 A}$

Similarly, the $\mathrm{COP}_{\text {mat }}$ for reverse Brayton cycle is equal to Eq. (9). $\Delta T_{\mathrm{ad}}$ is the adiabatic temperature span of SMA during the phase change process, which is related to the specific heat and specific entropy change of the SMA, as defined by Qian et al. (2015). A quick examination on Eq. (9) is to compare the theoretical prediction of $C O P_{\text {mat }}$ for nitinol wire with the previous measured data by Cui et al. (2012) and the projected $C O P_{\text {mat. }}$ The conditions for both $T_{\mathrm{c}}$ and $T_{\mathrm{h}}$ were maintained at room temperature, i.e. $295 \mathrm{~K}$ in the previous study. By choosing $A=120 \mathrm{~J} / \mathrm{kg}$ for compression from Table 1 , and $\Delta s=32 \mathrm{~J} / \mathrm{kg} \cdot \mathrm{K}$ from the and $\Delta T_{\text {ad }}=17 \mathrm{~K}$ based on the measured data for a $3 \mathrm{~mm}$ nitinol wire, the calculated $C O P_{\text {mat }}$ for compressing single wire is 11.5 , which has only $2.5 \%$ deviation from the measured data.

Note here we ignore the difference between loading/unloading adiabatic temperature spans. By comparing Eq. (8) with Eq. (9), one can clearly conclude that the reverse Brayton cycle is less 
efficient than the reverse Stirling cycle, as quantitatively indicated by Table 1 as well. Instead of using two constant temperature heat source/sink as discussed above, the reverse Brayton cycle is more efficient if two variable temperature heat source/sink are used.

$$
\gamma \equiv \frac{\Delta T_{a d}}{\Delta T_{l i f t}}
$$

An important criterion, $\gamma$, known as the so-called "non-dimensional latent heat", as defined in (Qian et al., 2015) is presented here in Eq. (10) and is used later in Table 1 and Eqs. (20-22).

\section{System cycle performance evaluation of a compressive thermoelastic cooling system under reverse Brayton cycle}

In this study, both analytical and numerical investigations are focused on the reverse Brayton cycle design, as shown in Figure 3. For a reverse Brayton cycle design with two beds, the time scale of phase change is much smaller than that of the heat transfer.

\subsection{Analytical expressions for COP and cooling capacity}

The derivation of the analytical COP and cooling capacity requires physical understanding of the solid-state material temperature change during a single cooling cycle.

Assuming:

- Lump temperature for solid-state materials

- Same heat transfer effectiveness for both solid-state materials during both cooling and heating process

- Same cooling and heating heat recovery efficiency

- Same adiabatic temperature span for stress induced phase change (the phase change from martensite to austenite has the same temperature span as the one from austenite to martensite)

For adiabatic phase change process 


$$
T_{2}-T_{1}=T_{4}-T_{5}=\Delta T_{a d}
$$

For solid-state material, heat transfer processes $(2 \rightarrow 3$ and $5 \rightarrow 6)$

$$
\frac{T_{2}-T_{3}}{T_{2}-T_{h}}=\frac{T_{6}-T_{5}}{T_{c}-T_{5}}=\varepsilon
$$

For heat recovery processes $\left(3 \rightarrow 4\right.$ and $\left.6 \rightarrow 1^{\prime}\right)$

$\frac{T_{3}-T_{4}}{T_{3}-T_{6}}=\frac{T_{1^{\prime}}-T_{6}}{T_{3}-T_{6}}=\eta_{H R}=\eta$

The material cooling capacity could be evaluated by

$$
\dot{Q}_{m a t}=\frac{m c_{p}}{t_{c y c}}\left(T_{6}-T_{5}\right)
$$

where $m$ is the total mass of solid-state material in a single bed, and $t_{\mathrm{cyc}}$ is the cycle duration, as shown in Figure 5.

When considering the entire cooling system, the fluid cooling capacity deviates from the material cooling capacity. This is because part of the cooling power released from the solid-state material is lost along the pipes to the heat exchanger due to fluid mixing, heat loss to ambient, and temperature cycling. Such difference caused by irreversibility could be measured by a factor less than 1, defined in the following equation:

$$
F \equiv \frac{\dot{Q}_{\text {fluid }}}{\dot{Q}_{\text {mat }}}
$$

On the other hand, the real power consumption to drive the solid-state material loadingunloading process also deviates from the theoretical value. This difference is due to motor efficiency $\eta_{\text {mot }}$, transmission efficiency $\eta_{\text {trsm }}$, and work-recovery efficiency $\eta_{\text {rec. }}$. A similar factor could be applied to evaluate this deviation, defined in the following manner: 


$$
D \equiv \frac{\dot{W}_{\text {ideal }}}{\dot{W}_{\text {real }}}=\eta_{\text {mot }} \eta_{\text {trsm }} \frac{w_{+}-w_{-}}{w_{+}-\eta_{\text {rec }} w_{-}}
$$

In the context of vapor compression heat pump, this factor $D$ is similar to the compressor efficiency. Work recovery is similar to a turbine, where part of the available energy from the high pressure refrigerant is re-used to reduce compressor work.

Based on the graphical interpretation in Figure 5, we have two more equations:

$$
\frac{\dot{Q}_{\text {mat }}}{\dot{Q}_{\text {latent }}}=\frac{T_{6}-T_{5}}{T_{2}-T_{1}}
$$

$$
\Delta T_{l i f t} \equiv T_{h}-T_{c}
$$

The system COP is defined as the ratio between gain and cost:

$$
\begin{aligned}
C O P & =\frac{\dot{Q}_{\text {fluid }}}{\dot{W}_{\text {real }}}=\frac{\dot{Q}_{\text {fluid }}}{\dot{Q}_{\text {mat }}} \cdot \frac{\dot{Q}_{\text {mat }}}{\dot{Q}_{\text {latent }}} \cdot \frac{\dot{Q}_{\text {latent }}}{\dot{W}_{\text {ideal }}} \cdot \frac{\dot{W}_{\text {ideal }}}{\dot{W}_{\text {real }}} \\
& =F \cdot \frac{\dot{Q}_{\text {mat }}}{\dot{Q}_{\text {latent }}} \cdot C O P_{\text {mat }} \cdot D
\end{aligned}
$$

The second term could be evaluated from Eqs. (11-14):

$$
\begin{aligned}
\frac{\dot{Q}_{\text {mat }}}{\dot{Q}_{\text {latent }}} & =\frac{\varepsilon\left(\Delta T_{a d}-\Delta T_{\text {lift }}(1-\eta)\right)}{\Delta T_{a d}[1+(1-\varepsilon)(1-2 \eta)]} \\
& =\frac{\varepsilon(\gamma+\eta-1)}{\gamma[1+(1-\varepsilon)(1-2 \eta)]}
\end{aligned}
$$

Based on the above discussion and use the $\mathrm{COP}_{\text {mat }}$ for reverse Brayton cycle in Eq. (9), the system COP and cooling capacity are:

$$
C O P=F \cdot \frac{\varepsilon(\gamma+\eta-1)}{\gamma[1+(1-\varepsilon)(1-2 \eta)]} \cdot D \cdot C O P_{\text {mat }}
$$




$$
\dot{Q}_{\text {fluid }}=F \cdot \frac{m c_{p} \Delta T_{l i f t}}{t_{c y c}} \cdot \frac{\varepsilon(\gamma+\eta-1)}{[1+(1-\varepsilon)(1-2 \eta)]}
$$

It should be noted that factor $F$ is not self-contained within the above equations set. It can be evaluated externally by dynamic modeling or experiment.

\subsection{Numerical model development}

In the numerical dynamic model, the following assumptions are used:

- The timescales of phase transformation and loading are negligible compared with that of heat transfer

- Radial heat transfer time scale is negligible compared with axial direction, $\mathrm{Bi}_{\delta}=0.01$

- Uniaxial loading and uniform phase transformation

- Constant thermophysical properties within the small temperature range of interest

- Incompressible flow and uniform velocity profile at any cross section inside the nitinol tube

- Uniform fluid temperature profile at any cross section inside the nitinol tube

- No heat transfer from nitinol tubes to surrounding

- No radiation heat transfer

It should be noted that the first assumption is crucial to the dynamic model simulation, because it not only decouples the problem, but also transforms a stiff problem to a normal problem and therefore, improves the robustness of the simulation. The adiabatic phase transformation process shown as $1 \rightarrow 2$ or $4 \rightarrow 5$ in Figure 3 , is completed within 0.1 second, which is two magnitudes less than the heat transfer/heat recovery time scale. Figure 6 shows the schematic of the thermoelastic cooling system model. There are four basic components in the model: thermoelastic material beds, heat source/sink, mechanical driver, and connecting pipes (three colors representing different loops). The two beds design enables heat recovery, work recovery of the mechanical driver and the continuous cooling/heating production. The 
mechanical driving system can be any linear actuator, i.e. linear screw jack driven by motors, or hydraulic cylinder driven by oil pump, which can move reciprocally to compress each bed one by one. When one bed is compressed, the other one is unloaded. During the loading process, the work recovery requires the unloading energy from the other bed to be applied in order to save the power consumption of the driving system. Referring to Figure 3 for SMA beds temperature change, the mechanical driving system and the HTF loops must operate and synchronize in a certain order to guarantee proper cycle operation, as specified in Table 2.

$$
\begin{aligned}
& \frac{\partial T_{s}}{\partial t}=\alpha_{s} \frac{\partial^{2} T_{s}}{\partial x^{2}}-\frac{h}{\delta \cdot\left(\rho c_{p}\right)_{s}}\left(T_{s}-T_{f}\right)+\frac{g^{\prime \prime \prime}}{\left(\rho c_{p}\right)_{s}} \\
& \frac{\partial T_{f}}{\partial t}=\alpha_{f} \frac{\partial^{2} T_{f}}{\partial x^{2}}-\frac{4 h}{I D \cdot\left(\rho c_{p}\right)_{f}}\left(T_{f}-T_{s}\right)-u_{f} \frac{\partial T_{f}}{\partial x}
\end{aligned}
$$

The governing equations of thermoelastic material beds are the energy equations for solid tube and fluid inside, as shown in Eqs. (23-24). For solid energy equation Eq. (23), the first term on the RHS identifies the conduction along axial direction (flow direction), and the second term measures the convective heat transfer between solid and fluid contact with solid. Most importantly, the last term is determined by the thermoelastic effect, which is positive during the austenite to martensite transformation process and negative during the opposite process. The term remains zero when there is no phase transformation. Assuming that the loading/unloading processes and the latent heat are independent on temperatures, this simplification makes sense since the time scale for phase change $(\sim 0.1 \mathrm{sec})$ is much smaller than the time scale for heat transfer $(\sim 1-10 \mathrm{sec})$. Despite an ideal scenario that the stress-strain relation could be decoupled from temperature, the assumption is valid for a cooling system level dynamic simulation. Such decoupling leads to a much easier calculation of the generation term, as indicated by Eq. (25). 
In Eq. (25), the loading process releases heat, therefore generation term is greater than zero when the deformation strain rate is greater than zero. Both latent heat released from the phase change process $\Delta h$ and mechanical stress induced deformation energy $w+$ are accounted, vice versa. It also holds for single phase heat transfer and heat recovery process, since the time derivative of normalized strain is zero when no phase change occurs. Here since we assume uniform phase change, the martensite phase fraction rate is the same as deformation strain rate. The strain profile is determined in Table 2.

$$
\begin{aligned}
& \left.\frac{\partial T_{s}}{\partial x}\right|_{x=0, x=L}=0 \\
& \left.T_{f}\right|_{x=0}=T_{f, \text { in }}
\end{aligned}
$$

Adiabatic boundary conditions are applied for solid in Eq. (26) and commonly used boundary conditions for fluid are set in Eq. (27).

$$
m_{c} c_{p, f} \frac{d T_{c}}{d t}=\dot{m}_{c} c_{p, f}\left(T_{i n}-T_{c}\right)+\dot{Q}_{c}
$$

A uniform temperature water tank model is applied for both the heat source/sink, as shown in Eq. (28). The heat source is assumed to have a heat rate of $\dot{Q}_{c}$, which is determined by a PID controller using $T_{\mathrm{c}}$ and $T_{\mathrm{c}, \text { set }}$ as control signals. The set points for heat source $T_{\mathrm{c}}$ and heat sink $T_{\mathrm{h}}$ are determined based on the temperature lift.

$$
\frac{\partial T_{f}}{\partial t}=\frac{k_{f}}{\kappa\left(\rho c_{p}\right)_{f}} \frac{\partial^{2} T_{f}}{\partial x^{2}}-\frac{4 h_{a i r}}{\kappa\left(\rho c_{p}\right)_{f} O D}\left(T_{f}-T_{a m b}\right)-\frac{u_{f}}{\kappa} \frac{\partial T_{f}}{\partial x}
$$


$\kappa=\frac{\left(m c_{p}\right)_{f}+\left(m c_{p}\right)_{s}}{\left(m c_{p}\right)_{f}}=\frac{\left(\rho c_{p}\right)_{f} I D^{2}+\left(\rho c_{p}\right)_{s}\left(O D^{2}-I D^{2}\right)}{\left(\rho c_{p}\right)_{f} I D^{2}}$

For the connecting pipes, only fluid energy equation is used, with a correcting factor $\kappa$ to account for the thermal mass contribution from solid pipe wall, as shown in Eqs. (29-30).

The valve/pump sequences specified in Table 2 are used to determine the flow rate and corresponding velocity for each pipe in Figure 6. When the valves are closed, it is assumed that the flow stops instantaneously without any delay, and vice versa. Water is used as the heat transfer fluid for all fluid loops. The following correlations are currently used to predict the pipe flow heat transfer coefficient $h$, for both regular pipes and thermoelastic material tubes (Bergman et al., 2011):

Laminar flow: $N u_{\mathrm{D}}=3.66$ (fully developed constant wall temperature)

Turbulent flow: $N u_{D}=0.023 \operatorname{Re}_{D}^{4 / 5} \operatorname{Pr}^{n}$ (Dittus-Boelter equation)

Similar to other cyclic operated cooling systems such as adsorption chiller, the thermoelastic cooling system instantaneous cooling capacity, or the RHS second term in Eq. (28), is also varying all the time. Instead, the time averaged cooling capacity $\overline{\dot{Q}}_{c}$ during the cyclic steady state condition is used, and COP is also evaluated based on the time averaged capacity, as shown in Eqs. (31-32):

$$
\begin{aligned}
& \overline{\dot{Q}}_{c}=\frac{\int_{0}^{t_{c y c}} \dot{Q}_{c} \mathrm{~d} t}{t_{c y c}} \\
& C O P=\frac{\overline{\dot{Q}}_{c} t_{c y c}}{W_{+}-\eta_{r e c} W_{-}} \eta_{m o t} \eta_{t r m s}
\end{aligned}
$$

In this study, it is assumed that $\eta_{m o t} \eta_{\text {trms }}=0.9$, and work recovery efficiency $\eta_{\text {rec }}=0.9$. 
To quantitatively study the thermoelastic cooling system performance, and investigate the most favorable material from a thermodynamic system perspective, necessary physical properties and loading test data are summarized in Table 1 for analytical and numerical modeling use in this study.

\section{Results and discussion}

\subsection{Analytical COP and cooling capacity}

Figures 9-11 shows the COP and cooling capacity curves predicted by Eqs. (21-22). The nondimensional latent heat $(\gamma)$ evaluated at $10 \mathrm{~K}$ lift is available in Table 1. Figure 7 shows a sensitivity analysis of heat recovery efficiency on the system COP, when the cycle duration remains constant. The maximum COP improvements for all three alloys are all beyond $100 \%$ between the worst case scenario $(\eta=0.3)$ and the ideal case $(\eta=1)$. Even when the heat recovery efficiency is 0.7 , the improvement is more than $50 \%$ compared with the worst case scenario. It should be noted that the heat recovery process favors more to those materials with higher specific heat, since the process saves more internal parasitic sensible heat for higher specific heat materials. Figure 8 indicates that any insufficient heat transfer (processes $2 \rightarrow 3,5 \rightarrow 6$ in Figure 5) will lead to significant performance deterioration. For normal operation conditions, the effectiveness is usually greater than 0.8 . The COP improvement from 0.8 to 1 is $19 \%$, which is not much significant as heat recovery efficiency. It should be noted that unlike the heat recovery efficiency, the COP improvement by heat transfer effectiveness is independent of SMA properties. Figure 9 plots how fast the performance reduces with respect to the system temperature lift. The VCC system COP is plotted as a baseline. Figure 9 indicates a concave decreasing trend, which could be depicted by the derivative of COP curves, interception of COP at $0 \mathrm{~K}$ temperature lift, and interception of maximum temperature lift when COP decreases to zero, in Eqs. $(33-35)$ : 
The Eq. (35) shows the expression of the maximum achievable temperature lift when there is no cooling or heating load, i.e. $\mathrm{COP}=0$ since there is no cooling benefit. Under the extreme case when the heat recovery efficiency becomes $100 \%$, there is no more limit on the maximum system temperature lift, and COP becomes independent on temperature lift as well, as indicated by Eq. (21). An intuitive way to explain this independency is to look back to Figure 5. As a result of heat recovery efficiency to be $100 \%$, bed 1 and 2 simply swap their temperatures from $3 \rightarrow 4$ and $6 \rightarrow 1$ ', which is not effected by how far away the heat source/sink lines are away.

\subsection{Effect of operating parameters on system performance}

Before discussing the effect of operating parameters, including flow rates and cycle duration, the temperature profiles are discussed in Figure 10. Figure 10 (a) plots the temperature profiles of two NiTi beds for four complete cooling cycles under the "cyclic steady state" condition. Cyclic steady state refers to the period that the any measured variables repeat the same pattern over cycles, such as the temperature profile at a certain location. All the simulation results used for discussion in this paper is sampled under such "cyclic steady state" condition. Figure 10 (a) is also comparable to the concept schematic in Figure 5. Figure 10 (b) shows the heat sink and source temperature variation in the same time frame as compared to Figure 10 (a). Note that the temperature variation is due to the cyclic operation nature of the system, since cooling and heating are only provided during heat transfer process. Figure 10 (c) plots the model predicted temperature profile of heat source and sink at a much wider time scale. The temperature lift 
determines the set points for heat sink and source, and the temperature curves are approaching their set points as controlled by two PID controllers. It should be mentioned that the heat recovery duration in this study is determined based on the following equation according to (Qian et al., 2015), unless otherwise noted:

$t_{H R}=t * \times\left(\frac{L}{u_{H R}}+\frac{L_{H R, p i p e}}{u_{H R, p i p e}}\right)$

The first term $t^{*}$ in Eq. (36) is the heat recovery coefficient, or a non-dimensional heat recovery time, and was found to be 1.2 in order to result in the optimum heat recovery efficiency. The two terms inside bracket measure the total time duration for the fluid to travel half of the heat recovery loop, which is equal to the time required to flow through one NiTi bed, in addition to the time required to flow through the connecting heat recovery pipes between two NiTi tubes beds.

Figure 11 shows that the cycle duration is the most significant contributing factor to the system performance. A longer cycle has a more "complete" heat transfer and a more reversible heat recovery, therefore both heat transfer effectiveness $(\varepsilon)$ and heat recovery efficiency $(\eta)$ increase. As indicated by Eq. (21), the COP increases with a higher $\varepsilon$ and $\eta$. In fact, $\varepsilon$ is improved from around 0.3 to above 0.95 when cycle duration is improved from 6 seconds to 20 seconds, and $\eta$ from 0.2 to 0.6 as well. Accordingly, for the $u=0.8 \mathrm{~m} / \mathrm{s}$ case, the COP, or cooling capacity per cycle is increased from 0.65 to 1.46 (124\%) from 6 seconds to 10 seconds, while the cycle duration endured $66 \%$ longer. Meanwhile, the work per cycle remains the same. The COP further increased from 1.46 to 1.93 (32\%) but at a cost of increasing $100 \%$ cycle duration, and therefore the time averaged cooling capacity dropped after 10 seconds. As a competing result, the time averaged cooling capacity only increases from $67 \mathrm{~W}$ to $83 \mathrm{~W}$ between 6 seconds to 10 seconds cycle duration, but is reduced to $53 \mathrm{~W}$ thereafter.

Similarly, Figure 12 plots the contribution of another important parameter to the performance, the flow rate (or corresponding velocity over the NiTi tube) during the heat transfer process $u_{\mathrm{HT}}$. 
A higher flow rate increases convective heat transfer coefficient, and therefore, the heat transfer effectiveness is improved from 0.7 to 0.78 when flow velocity increases from $0.1 \mathrm{~m} / \mathrm{s}$ to $0.4 \mathrm{~m} / \mathrm{s}$ but remains almost constant beyond that point. Since the cycle duration remains constant, both $\mathrm{COP}$ and cooling capacity increase until a plateau is reached when $u_{\mathrm{HT}}=0.4 \mathrm{~m} / \mathrm{s}$. This is because the majority bottleneck limiting a higher effectiveness is the heat transfer duration rather than heat transfer flow rate at that point. The second observation is that the COP/capacity curves have tiny oscillation at different flow rates rather than stay monotonically increasing to saturation values. This is due to the temperature oscillation transient effect during the heat transfer process when the thermal mass of fluid inside the heat source/sink is in the same magnitude as the NiTi bed fluid. The same figure also indicates that with a longer cycle duration, this transient effect reduces significantly.

As to the heat recovery flow velocity $u_{\mathrm{HR}}$, Figure 13 shows that an optimum $u_{\mathrm{HR}}$ exists but differs under different cycle duration. A slower heat recovery process is considered to be a more reversible design (Qian et al., 2015), but requires a longer heat recovery duration according to Eq. (36), and therefore, left less time for heat transfer. By using the analytical COP in Eq. (21) again, the first effect is that a smaller $u_{\mathrm{HR}}$ returns a higher heat recovery efficiency $\eta$, with a side effect of smaller heat transfer effectiveness $\varepsilon$. In fact, for the 12 seconds $t_{\text {cyc }}$ case, $\eta$ is improved from 0.15 to 0.46 when $u_{\mathrm{HR}}$ reduces from $1 \mathrm{~m} / \mathrm{s}$ to $0.4 \mathrm{~m} / \mathrm{s}$, at a cost of losing $\varepsilon$ from 0.95 to 0.87 . Below $0.4 \mathrm{~m} / \mathrm{s}$ threshold, even with higher $\eta$ (up to 0.55 ), the system overall capacity or COP still reduces, since the effectiveness $\varepsilon$ reduces dramatically from 0.87 to 0.52 . These two major contradictory effect result in the existence of the optimum $u_{\mathrm{HR}}$.

\subsection{Effect of solid-state bed structural parameters on system performance}

Unlike fluid refrigerants used in vapor compression systems, solid-state materials used in thermoelastic cooling have unique shapes and geometries. The geometries could significantly contribute to the transient behavior during the heat transfer and heat recovery processes. 
Therefore, the effect of geometries was investigated while the overall NiTi volume is maintained constant to guarantee the same amount of material latent heat.

As shown in Figure 11, the system cooling capacity does not increase linearly when the cycle frequency increases, which is due to low heat transfer effectiveness and heat recovery efficiency. In other words, the NiTi tube's thermal mass does not allow high frequency heat transfer, and thus it becomes a limiting factor to increase the cycle frequency. One way to resolve this issue is to use NiTi tubes with thinner wall. Figure 14 shows the effect of NiTi tube wall thickness on both COP and cooling capacity. The NiTi tubes outside diameter (OD) remains constant while the wall thickness varies. However, the cooling capacity/COP do not show an expected trend of increase as wall thickness decreases. To better understand the physics, Figure 15 plots the bed cooling capacity curves. The significant difference between Figure 14 and Figure 15 is due to the fact that the amount of cooling extracted from NiTi tubes do increase when reducing the wall thickness, but the cooling power could not be delivered to the heat source $T_{\mathrm{c}}$. The cooling is lost along the fluid lines, majorly contributed by fast cycling loss as described by factor $F$ in Eq. (15). For the 12 seconds $t_{\text {cyc }}$ case, $\mathrm{F}$ is only $0.2 \%$ for $0.15 \mathrm{~mm}$ wall thickness point, and increases from $2 \%$ to $62 \%$ monotonically with wall thickness. As a result, it is not recommended to use thin wall NiTi tubes to boost the cycle frequency.

Figure 16 shows the impact of NiTi tube length on the system COP and cooling capacity. The influence of tube length is not as significant as other parameters shown before. Longer tube slightly reduces the fluid heat transfer driven potential since the fluid temperature changes more along the NiTi tubes, and therefore, has a slightly negative impact on the heat transfer effectiveness $\varepsilon$, i.e. from 0.87 to 0.8 . The heat recovery is considered to be more reversible with a longer tube length, and therefore, NiTi tube length has a slightly positive impact on the heat recovery efficiency $\eta$, i.e. from 0.4 to 0.46 . The combination of these two competing effects contributes to the curves shown in Figure 16. 


\subsection{Loss contribution summary}

Previous sessions discuss how the system COP is determined by the operating and geometric parameters. This session focuses on an overview of how the COP is varying with various losses. Figure 17 (a) is a stacked bar chart showing how the COP is degrading from Carnot COP to $\mathrm{COP}_{\text {mat }}$, and from material level all the way down to the system COP including the parasitic pump loss. The two $\mathrm{COP}_{\text {mat }}$ are evaluated using Eqs. (8-9) under isothermal and adiabatic compression, respectively. These two numbers could be boosted with other better alloys, as their mechanical properties and fatigue life are within tolerance. The first stage loss is due to material phase change irreversibility, which is also measured by the material constant $A$ in Eqs. (8-9). Unlike liquid-vapor phase change in equilibrium, solid-state phase change is highly irreversible contributed by "friction" interaction between different domains. The second stage loss is due to inefficiency of adiabatic compression, since the constant temperature heat source/sink do not match with the variable temperature heat transfer process in a reverse Brayton cycle. The next stage loss is due to mechanical driving system inefficiency, which is also measured by the factor $D$ defined in Eq. (16). When assuming a 90\% motor efficiency, and $90 \%$ work recovery efficiency, we can get the $\mathrm{D} \sim 0.70$. The fourth stage loss is due to heat transfer effectiveness and heat recovery efficiency being less than $100 \%$, which is shown in Eq. (20). The $\mathrm{COP}_{\text {bed }}$ equals 3.7 for a typical case simulation. The last stage loss is due to cyclic loss together with pumps parasitic power consumption. Factor $F$ in Eq. (10) measures the cyclic loss, which is due to cyclic heating/cooling of fluid and corresponding pipe walls. If we consider heat transfer fluid pumps power consumption, assuming it to be equal to $20 \%$ of motor work, a system COP of 1.7 is achieved. This typical case evaluation is a starting point, since it's a random design without optimization. The previous parametric studies indicate that a lot of design and operating parameters do have optimum solution, therefore, it is possible to reduce the third and fourth stages losses through optimizing the operating and geometric parameters. It is also possible to use the hybrid cycle instead of the reverse Brayton cycle to improve the $\mathrm{COP}_{\text {mat }}$. With a conservative 
estimation with no improvement on cyclic loss and pump work consumption, a COP improvement estimation is then plotted on the right side of Figure 17, assuming first to fourth stages losses could be reduced to half compared to the left side baseline scenario. The system $\mathrm{COP}$ is estimated to be 7.7 at $10 \mathrm{~K}$ lift under this estimation. A more conservative estimation could also be made, assuming the first stage loss remains the same since motor efficiency could not be improved significantly, with a system COP of 5.2. The detailed investigation on how much those methods improve the system performance will be quantitatively discussed in the future studies.

\section{Conclusions}

This study investigated the thermodynamic cycle analysis of thermoelastic cooling systems. Three types of cycle design were demonstrated on the T-s and stress-strain diagrams, applicable for both tensile driving mode and compressive driving mode. For the reverse Brayton cycle, the derived physics based analytical COP equation can be used as a simple calculation tool for future studies. The key parameters including the heat transfer effectiveness, the heat recovery coefficient and cyclic loss factor used in the analytical model can be derived from the developed dynamic model. Parametric studies indicated that for future prototype development and improvement studies, the following parameters are important and should be optimized: cycle duration, heat recovery flow rate, SMA tube wall thickness and length. Among them, the cycle duration is most important. COP can be enhanced more than $30 \%$ by switching to a longer cycle duration, with a compromise of losing $37 \%$ cooling capacity. Finally, the breakdown COPs of the reverse Brayton design compressive thermoelastic cooling system were discussed. A baseline system COP considering driving motor efficiency and necessary parasitic pump power consumption is 1.7 , and an estimated system COP with improvement ranges from 5.2 to 7.7 , all evaluated under $10 \mathrm{~K}$ lift. Possible performance improvement methods include looking for more efficient SMA material, optimizing operating and geometric parameters, better design of heat transfer loops or use high 
efficient pumps, and more efficient design of mechanical driving systems. Overall, based on the modeling results from current study, this new cooling technology is promising but also challenging, and requires more research effort to demonstrate its potential in real prototype and optimize its performance.

\section{Acknowledgement}

The authors gratefully acknowledge the support of this effort from the U.S. DOE and the Center for Environmental Energy Engineering (CEEE) at the University of Maryland. This work was supported by DOE ARPA-E DEAR0000131.

\section{References}

Ahler, M., 1975. On the usefulness of Martensitic transformations for energy conversion. Scr. Metall. 9, 71-74.

Bergman, T.L., Lavine, A.S., Incropera, F.P., Dewitt, D.P., 2011. Fundamentals of Heat and Mass Transfer $\left(7^{\text {th }}\right.$ edition). John Wiley \& Sons.

Bonnot, E., Romero, R., Manosa, L., Vives, E., Planes, A., 2008. Elastocaloric effect associated with the Martensitic transition in shape-memory alloys. Phys. Rev. Lett. 100. DOI: 10.1103/PhysRevLett.100.125901.

Chen, Y., Zhang, X., Dunand, D.C., Schuh, C.A., 2009. Shape memory and superelasticity in polycrystalline Cu-Al-Ni microwires. Appl. Phys. Lett. 95. DOI: 10.1063/1.3257372.

Cui, J., Wu, Y., Muehlbauer, J., Hwang, Y., Radermacher, R., Fackler, S., et al., 2012. Demonstration of high efficiency elastocaloric cooling with large $\Delta \mathrm{T}$ using NiTi wires. Appl. Phys. Lett. 101. DOI: 10.1063/1.4746257.

Cunningham, B., Ashbee, K.H.G., 1977. Marmem engines. Acta. Metall. 25, 1315-1321. 
Delaey, L., Lepeleire, G.D., 1976. The temperature-entropy diagram of "solid state engines" and "solid state heat pumping systems" with shape memory alloys. Scr. Metall. 10, 959-964.

Friend, C.M., Hamilton, S., 1995. The thermomechanical behavior of a metastable Cu-Al-Ni single crystal alloy. J. Phys. IV Fr. 5. DOI: 10.1051/jp4:1995269.

Furst, S.J., Crews, J.H., Seelecke, S., 2012. Numerical and experimental analysis of inhomogeneities in SMA wires induced by thermal boundary conditions. Continuum Mech. Therm. 24, 485-504.

Gall, K., Sehitoglu, H., Maier, H., Jacobus, K., 1998. Stress-induced Martensitic phase transformations in polycrystalline $\mathrm{CuZnAl}$ shape memory alloys under different stress states. Metall. Mater. Trans. A 29, 765-773.

Gil, F.J., Planell, J.A., 1999. Thermal efficiencies of NiTiCu shape memory alloys. Thermochim. Acta. $327,151-154$.

Gu, H.M., Qian, X.S., Li, X.Y., Craven, B., Zhu, W.Y., Cheng, A.L., et al., 2013. A chip scale electrocaloric effect based cooling device. Appl. Phys. Lett. 102, 122904. DOI: 10.1063/1.4799283.

Huang, W, 2003. On the selection of shape memory alloys for actuators. Mater. Design. 23, 11-19. Jacobs, S., Auringer, J., Boeder, A., Chell, J., Komorowski, L., Leonard, J., Zimm, C., 2014. The performance of a large-scale rotary magnetic refrigerator. Int. J. Refrigeration 37, 84-91.

Jani, J.M., Leary, M., Subic, A., Gibson, M.A., 2014. A review of shape memory alloy research, applications and opportunities. Mater. Design. 56, 1078-1113.

Jia, Y., Ju, Y.S., 2012. A solid-state refrigerator based on the electrocaloric effect. Appl. Phys. Lett. 100, 242901. DOI: 10.1063/1.4729038. 
Kanada, T., 2008. A New drive system using a shape memory alloy (SMA) heat engine and its applications. J. Optoelectron Adv. Mater. 10, 1061-1063.

Kaneko, K., Enomoto, K., 2009. Development of reciprocating heat engine using shape memory alloy (ratcheting type drive system with self-drive rotational valve). Trans. Jpn. Soc. Mech. Eng. $75,363-369$.

Lashley, J.C., Drymiotis, F.R., Safarik, D.J., Smith, J.L., 2007. Contribution of low-frequency modes to the specific heat of $\mathrm{Cu}-\mathrm{Zn}-\mathrm{Al}$ shape-memory alloys. Phys. Rev. B 75, 064304. DOI: 10.1103/PhysRevB.75.064304.

Liu, Y., 2004. The work production of shape memory alloy. Smart Mater. Struct. 13, 552-561.

Manosa, L., Planes, A., Ortin, J., 1993. Entropy change of martensitic transformation in Cu-based shape-memory alloys. Phys. Rev. B 48, 3611-3619.

Manosa, L., Planes, A., Vives, E., 2009. The use of shape-memory alloys for mechanical refrigeneration. Funct. Mater. Lett. 2, 73-78.

Manosa, L., Farnos, S.J., Vives, E., Planes, A., 2013. Large temperature span and giant refrigerant capacity in elastocaloric $\mathrm{Cu}-\mathrm{Zn}-\mathrm{Al}$ shape memory alloys. Appl. Phys. Lett. 103. DOI: $10.1063 / 1.4832339$.

Otsuka, K., Wayman, C.M., 1998. Shape memory materials. Cambridge University Press, Cambridge.

Picornell, C., Pons, J., Cesari, E., 2004. Stress-temperature relationship in compression mode in Cu-Al-Ni shape memory alloys. Mater. Trans. 45, 1679-1683.

Picornell, C., Pons, J., Cesari, E., 2001. Stabilisation of Martensite by applying compressive stress in Cu-Al-Ni single crystals. Acta. Mater. 49, 4221-4230. 
Qian, S., Ling, J., Muehlbauer, J., Hwang, Y., Radermacher, R, 2015. Study on high efficient heat recovery cycle for thermoelastic cooling. Int. J. Refrigeration (Submitted).

Reid, R.S., Ward, W.C., Swift, G.W., 1998. Cyclic thermoacoustics with open flow. Phys. Rev. Lett. 80, 4617-4620.

Rodriguez, C., Brown, L.C., 1980. The thermal effect due to stress-induced Martensite formation in $\beta$-CuAlNi single crystals. Metall. Mater. Trans. A 11, 147-150.

Sarlah, A., Kitanovski, A., Poredos, A., Egolf, P.W., Sari, O., Gendre, F., et al., 2006. Static and rotating active magnetic regenerators with porous heat exchangers for magnetic cooling. Int. J. Refrigeration 29, 1332-1339.

Sato, Y., Yoshida, N., Tanabe, Y., Fujita, H., Ooiwa, N., 2008. Characteristics of a new power generation system with application of a shape memory alloy engine. Electr. Eng. Jpn. 165, 8-15.

Schiller, E.H., 2002. Heat engine driven by shape memory alloys: prototyping and design. Master of Science (MS), Virginia Tech.

Sharp, J., Bierchenk, J., Lyon, H.B., 2006. Overview of solid-state thermoelectric refrigerators and possible applications to on-chip thermal management. P. IEEE 94, 1602-1612.

Shin, M., Kim, C. Chuang, Y., Jee, K., 1987. USA Patent No. US4683721 A.

Sittner, P., Novak, V., 2000. Anisotropy of Martensitic transformations in modeling of shape memory alloy polycrystals. Int. J. Plasticity 16, 1243-1268.

Smith, J.F., Luck, R., Jiang, Q., Predel, B., 1993. The heat capacity of solid Ni-Ti alloys in the temperature range 120 to 800 K. J. Ph. Equilib. 14, 494-500.

Swift, G.W., Gardner, D.L., Backhaus, S., 1999. Acoustic recovery of lost power in pulse tube refrigerators. J. Acoust. Soc. Am. 105, 711-724. 
Tong, H.C., Wayman, C.M., 1974. Characteristic temperatures and other properties of thermoelastic martensites. Acta. Metall. 22, 887-896.

Vasile, C., Muller, C., 2006. Innovative design of a magnetocaloric system. Int. J. Refrigeration $29,1318-1326$.

Wakjira, J.F., 2001. The VT1 shape memory alloy heat engine design. Master of Science (MS): Virginia Tech.

Wayman, C.M., Tong, H.C., 1975. On the efficiency of the shape memory effect for energy conversion. Scr. Metall. 9, 757-760.

Yazaki, T., Biwa, T., Tominaga, A., 2002. A pistonless Stirling cooler. Appl. Phys. Lett. 80, 157159.

Yu, B., Liu, M., Eggolf, P.W., Kitanovski, A., 2010. A review of magnetic refrigerator and heat pump prototypes built before the year. Int. J. Refrigeration 33, 1029-1060.

Zhu, J.J., Liang, N.G., Liew, K.M., Huang, W.M., 2001a. Energy conversion in shape memory alloy heat engine part I: theory. J Intell. Mater. Syst. Struct. 12, 127-132.

Zhu, J.J., Liang, N.G., Huang, W.M., Liew, K.M., 2001b. Energy conversion in shape memory alloy heat engine part II: simulation. J. Intell. Mater. Syst. Struct.12, 133-140.

Zimm, C., Boeder, A., Chell, J., Sternberg, A., Fujita, A., Fujieda, S., et al., 2006. Design and performance of a permanent-magnet rotary refrigerator. Int. J. Refrigeration 29,1302-1306.

Ziolkowski, A., 1993. Theoretical analysis of efficiency of shape memory alloy heat engines (based on constitutive models of pseudoelasticity). Mech. Mater. 16, 365-377. 


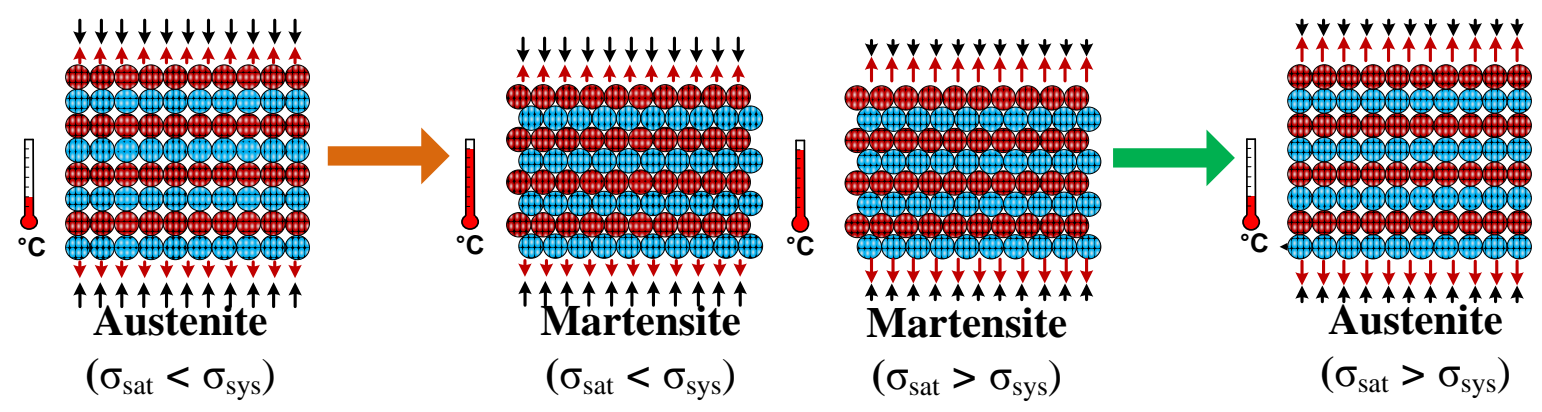

(a) Stress induced phase change releasing latent heat $\left(\sigma_{\text {sat }}<\sigma_{\text {sys }}\right)$

(b) Releasing stress leads to reversed phase change and absorbing latent heat

$$
\left(\sigma_{\text {sat }}>\sigma_{\text {sys }}\right)
$$

Figure 1: Illustration of martensitic phase change processes. 


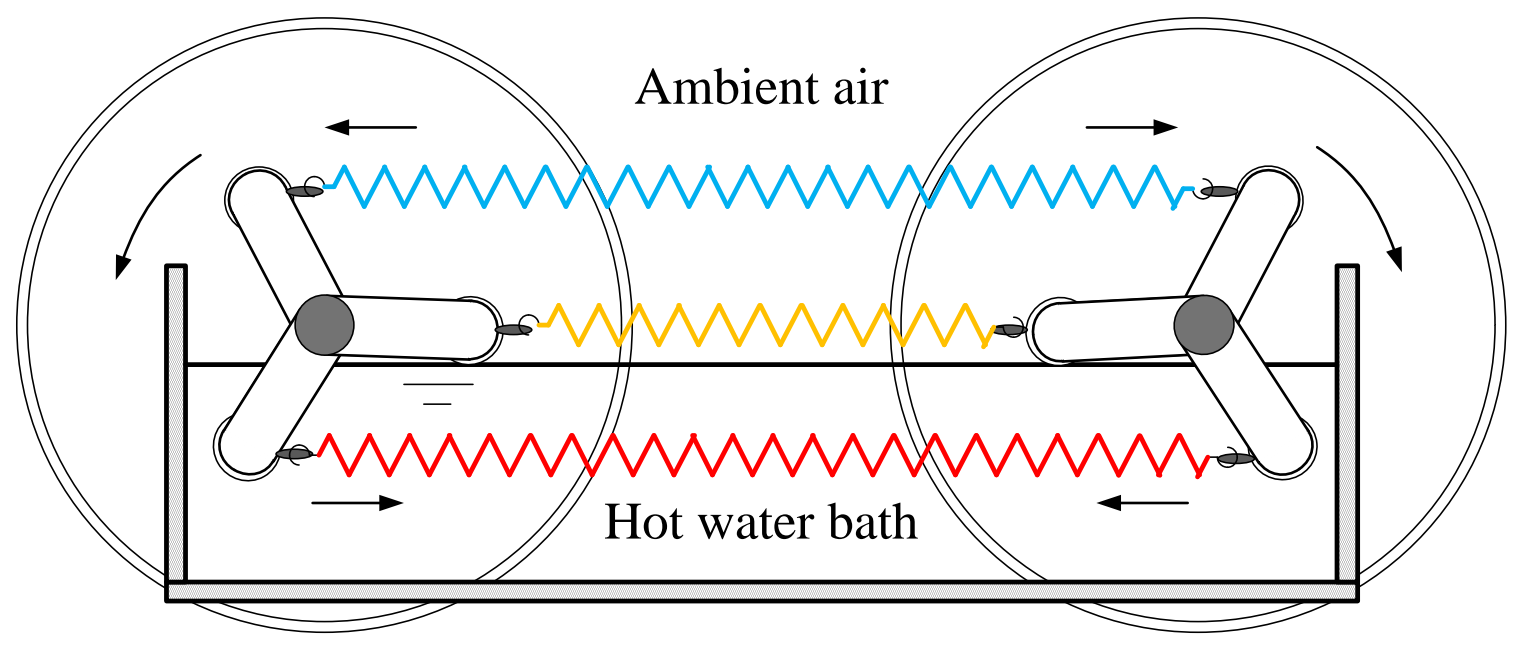

Figure 2: Illustration of a twin-crank SMA heat engine design using nitinol wires without any regenerator or heat recovery device (Shin et al., 1987). 

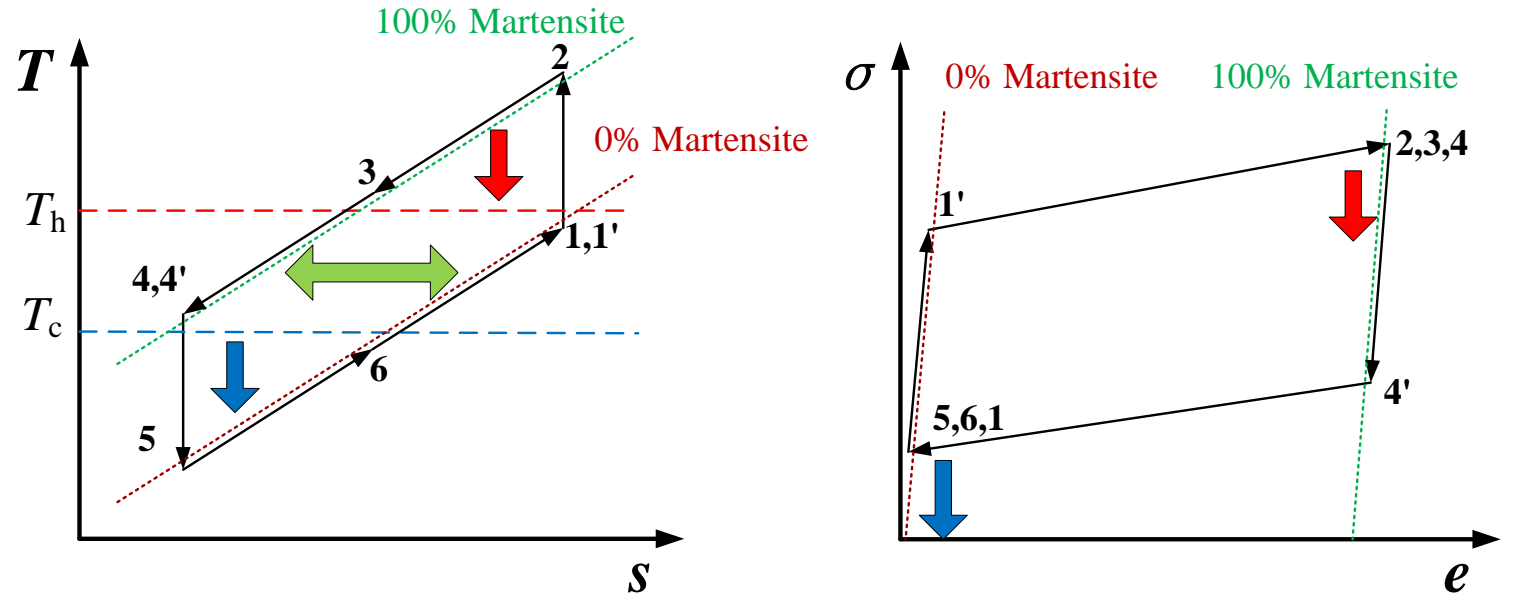

Figure 3: Illustration of reverse Brayton cycle and its variation as a thermoelastic cooling cycle. 

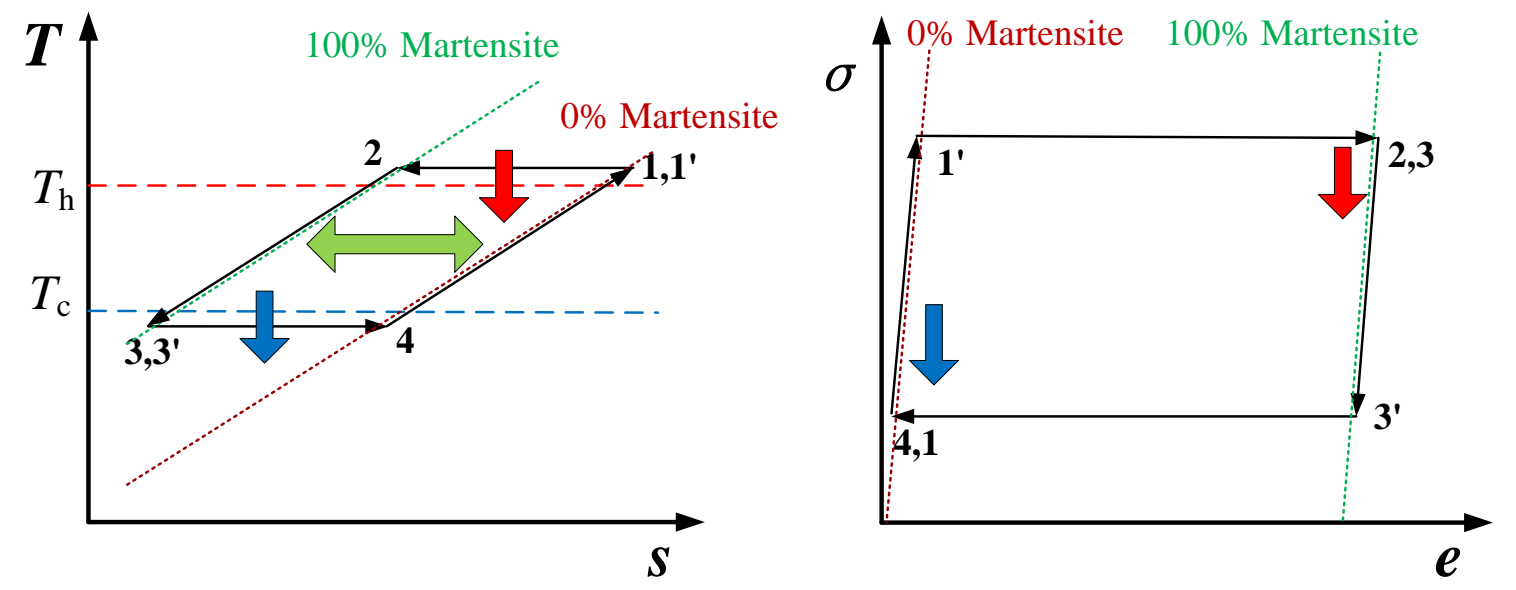

Figure 4: Illustration of reverse Stirling cycle and its variation as a thermoelastic cooling cycle. 


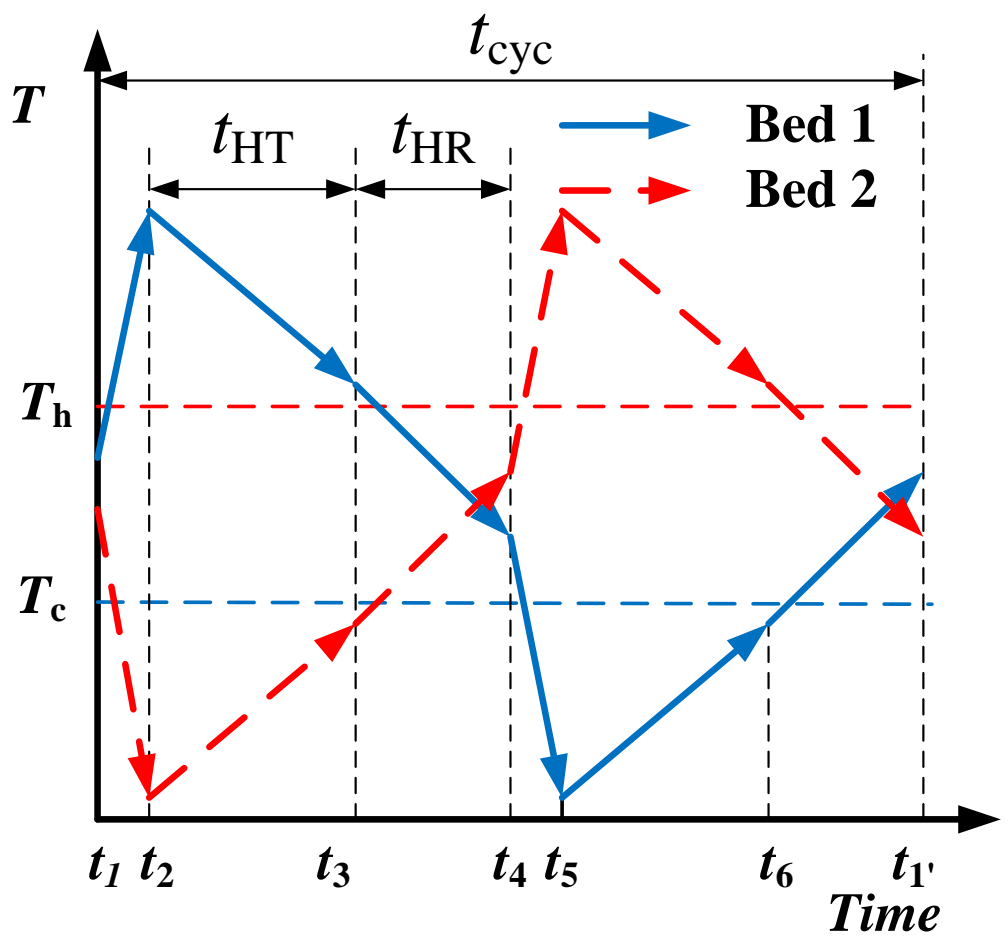

Figure 5: Illustration of the temperature profiles of solid-state thermoelastic SMA beds during one cooling cycle. 


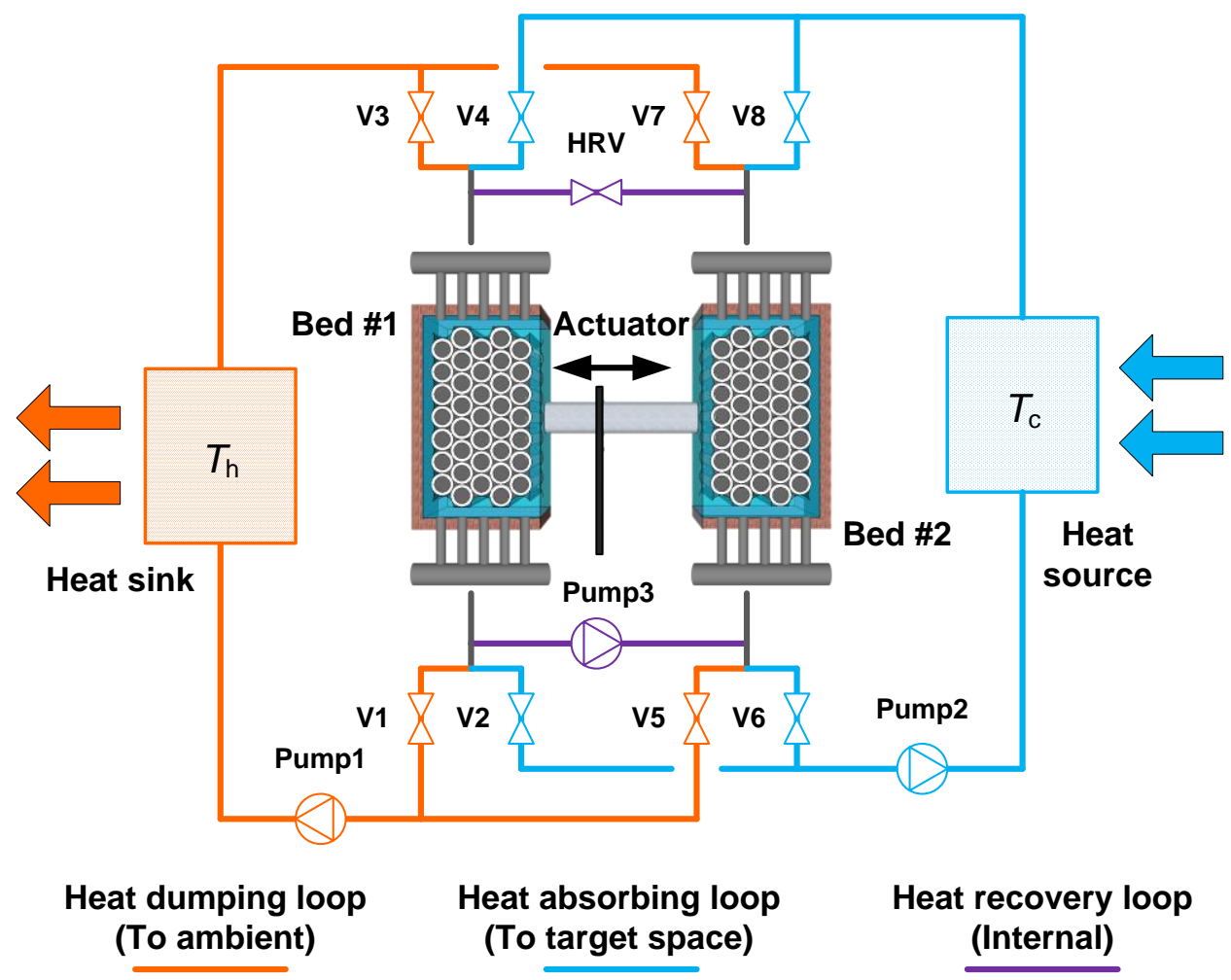

Figure 6: Schematic of the heat transfer fluid loop used for the numerical model. 


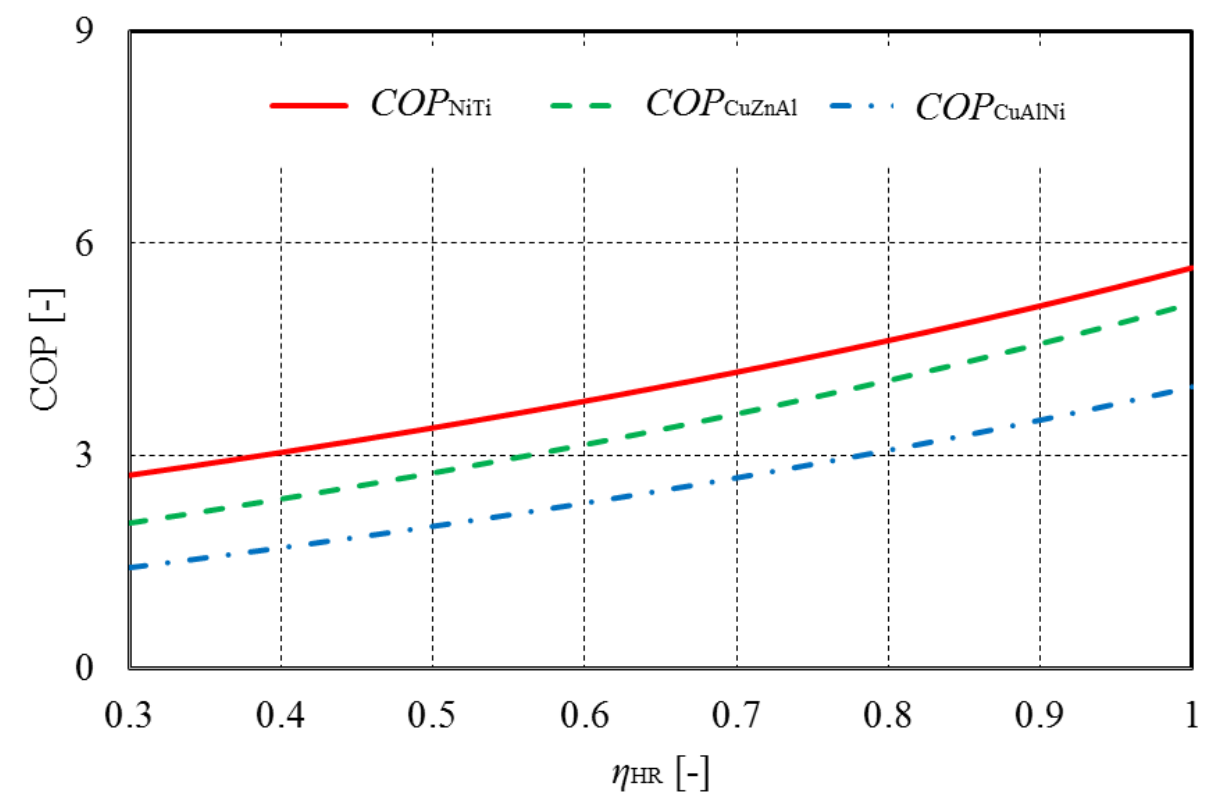

Figure 7: Analytical COP as a function of heat recovery efficiency (Three SMAs compressive loading mode, $F=0.9, \Delta T_{\text {lift }}=10 \mathrm{~K}, \varepsilon=0.8, D=0.85$ ). 


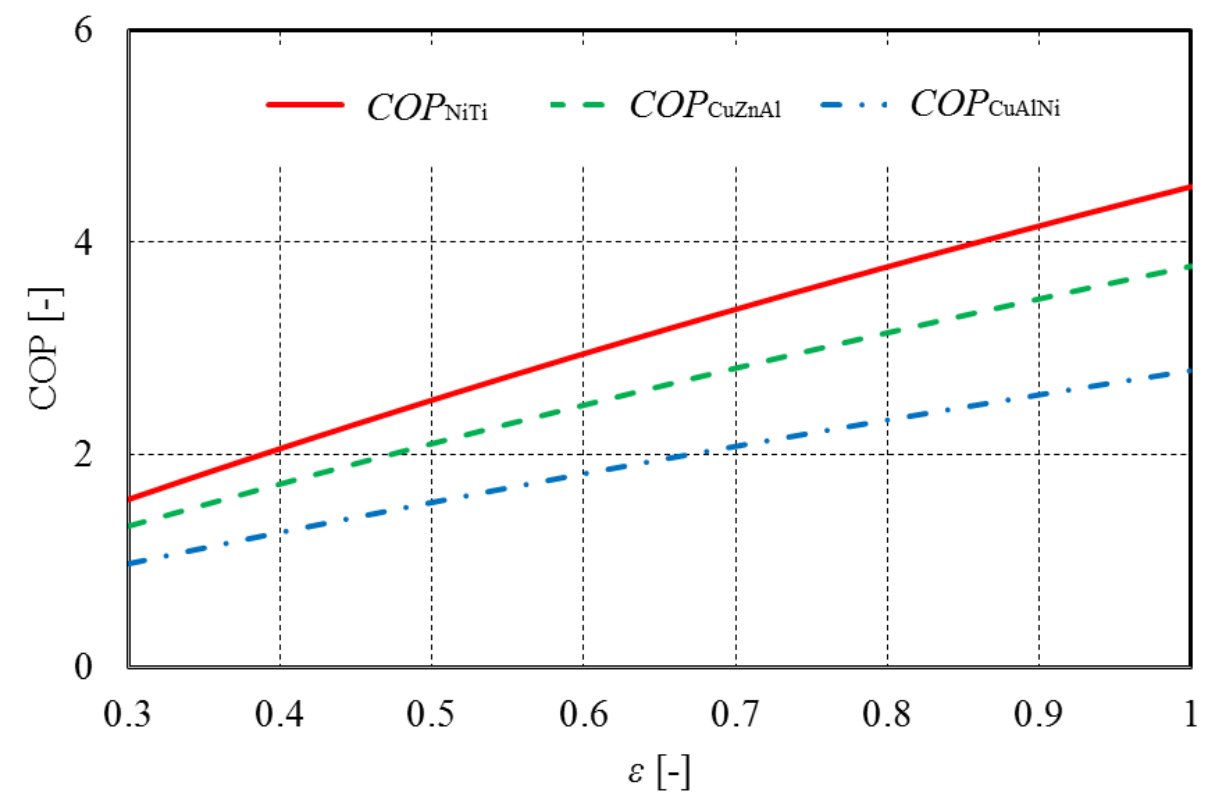

Figure 8: Analytical COP and cooling capacity as a function of heat transfer effectiveness (Three SMAs compressive loading mode, $F=0.9, \Delta T_{\text {lift }}=10 \mathrm{~K}, \eta=0.6, D=0.85$ ). 


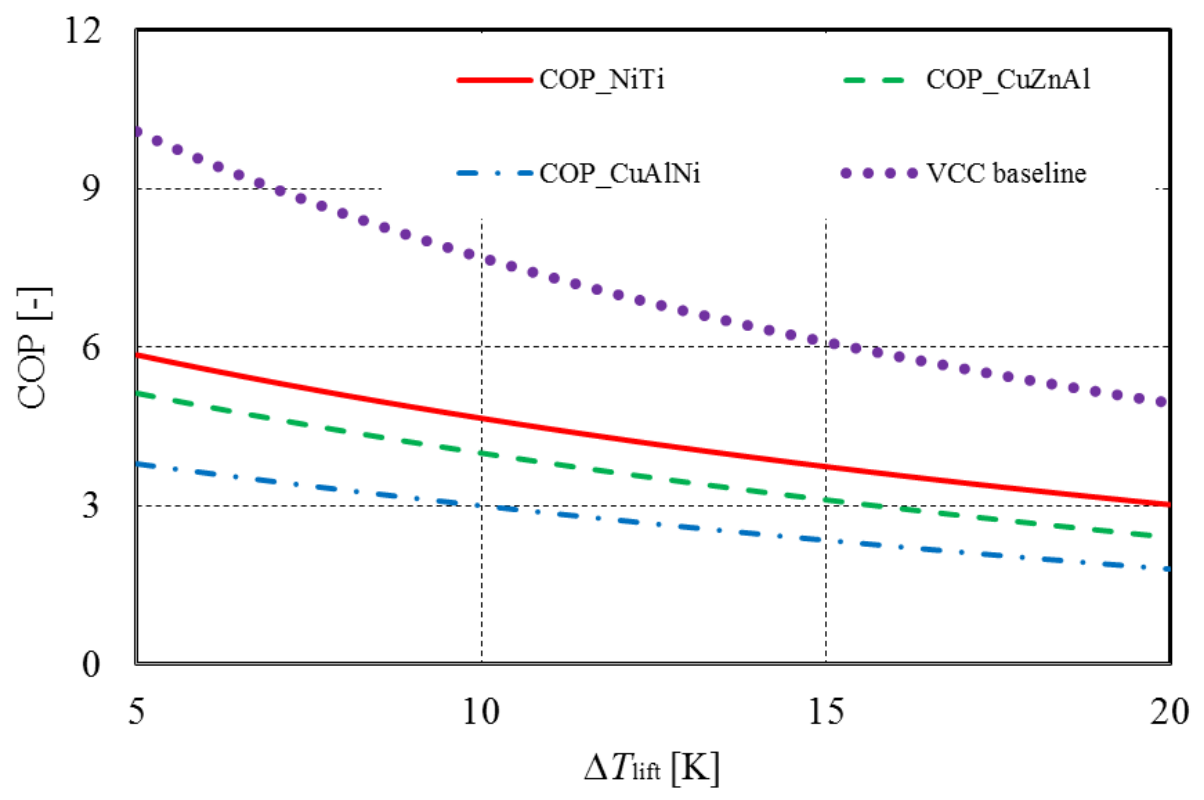

Figure 9: Analytical COP and cooling capacity as a function of temperature lift (Three SMAs compressive loading mode compressive loading mode, $F=0.9, \varepsilon=0.95, \eta=0.7, D=$ 0.85). 


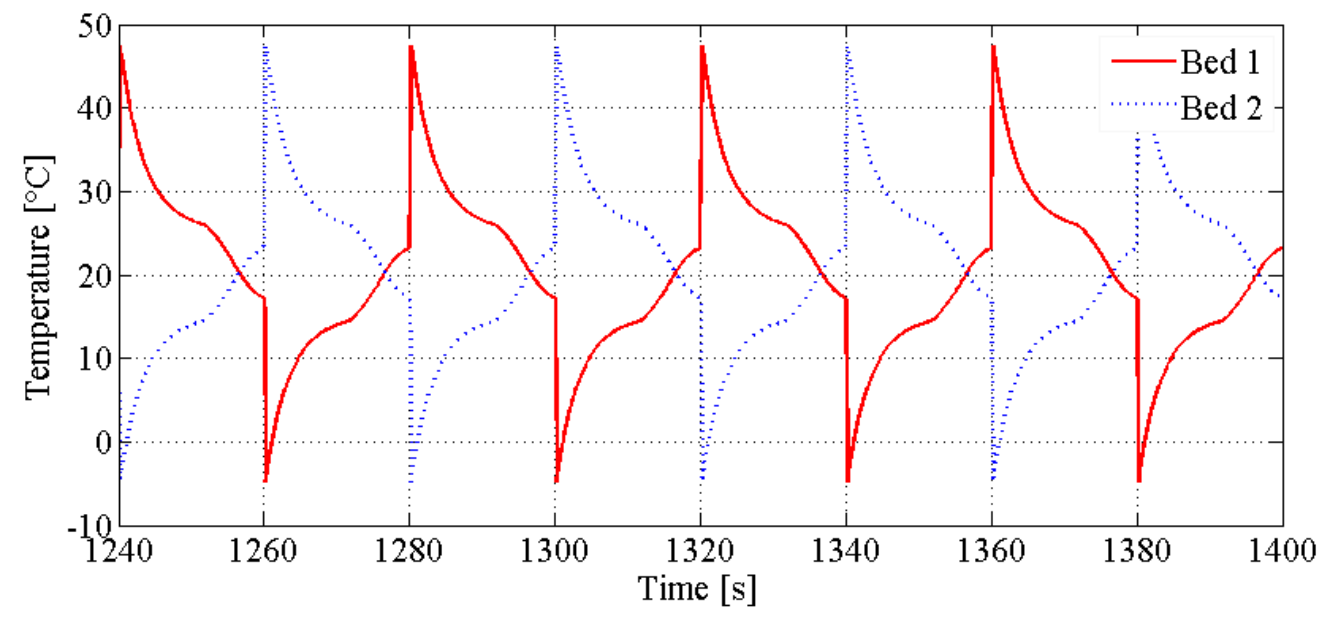

(a) Temperature profiles of two NiTi beds (solid) during the cyclic steady state sampling period.

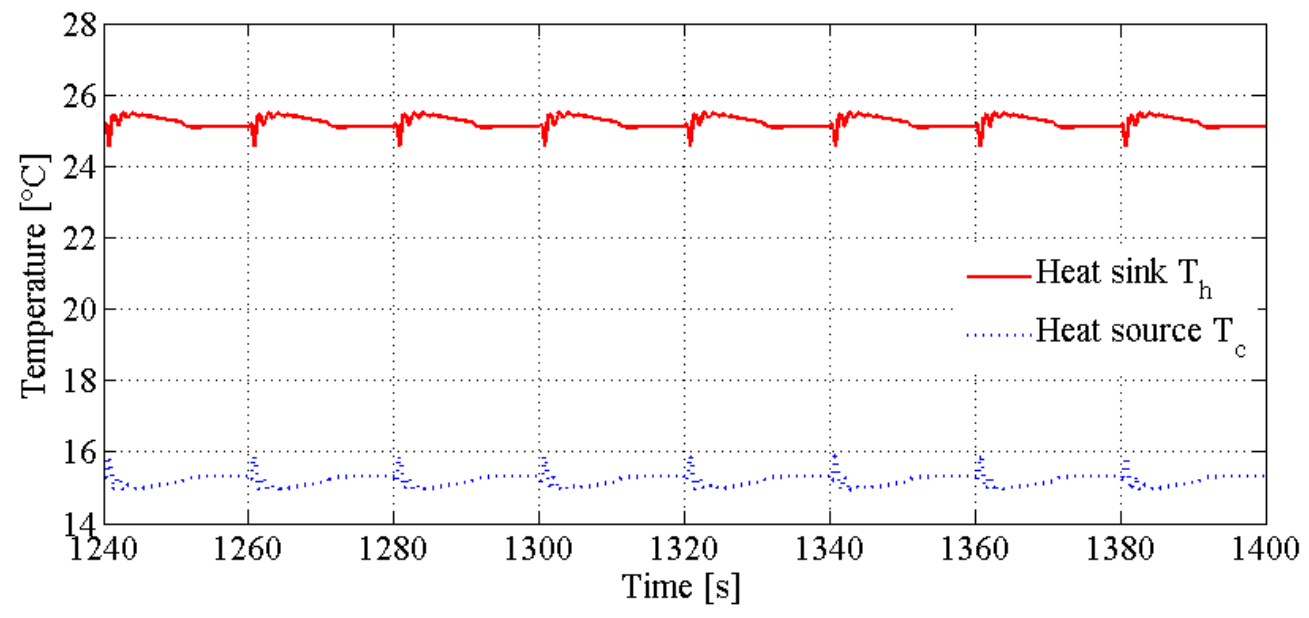

(b) Temperature profiles of heat source and heat sink. 


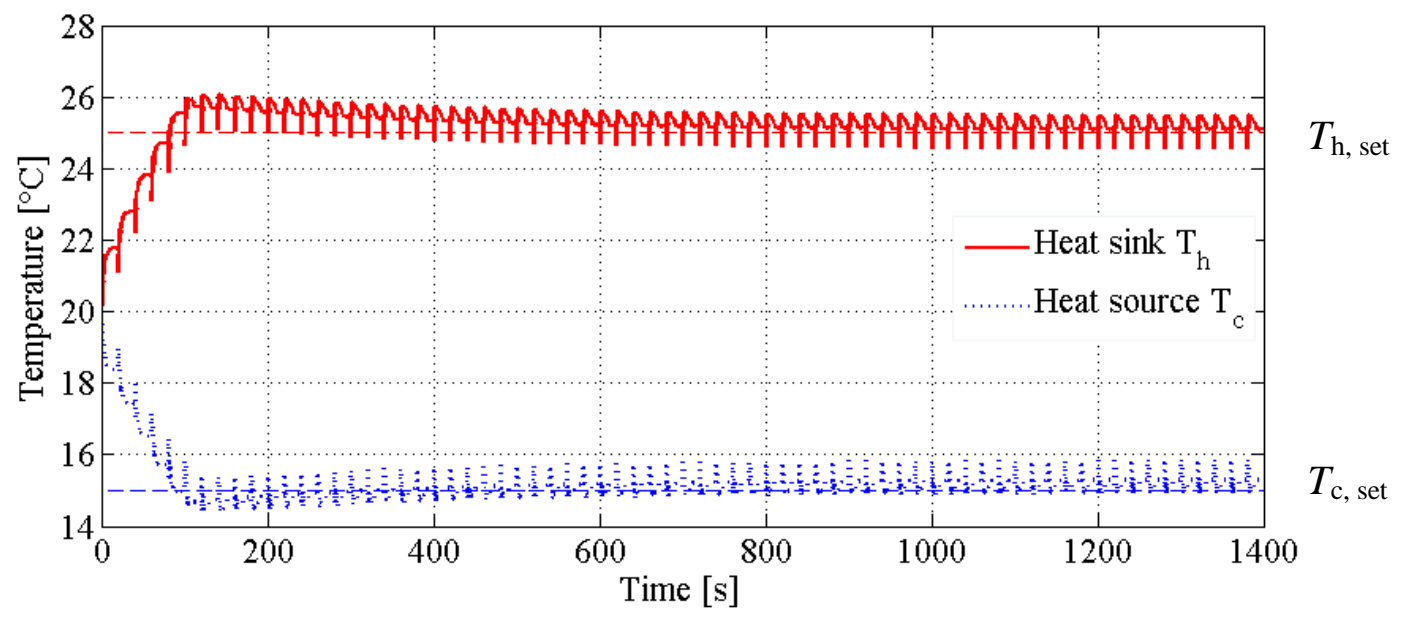

(c) Temperature profiles of heat source and heat sink. (Two horizontal dashed lines are set points for heat sink and heat source, $T_{\mathrm{c}, \text { set }}=15^{\circ} \mathrm{C}, T_{\mathrm{h}, \mathrm{set}}=25^{\circ} \mathrm{C}$ )

Figure 10: Temperature profiles predicted by the numerical model (NiTi alloy, $u_{\mathrm{HT}}=1.2$ $\mathrm{m} / \mathrm{s}, u_{\mathrm{HR}}=0.1 \mathrm{~m} / \mathrm{s}, \mathrm{L}=0.254 \mathrm{~m}, \mathrm{OD}=0.005 \mathrm{~m}, \mathrm{ID}=0.004 \mathrm{~m}, \mathrm{~N}=19, \Delta T_{\text {lift }}=10 \mathrm{~K}$, half cycle duration $\left.t_{\mathrm{cyc}}=20 \mathrm{~s}\right)$. 

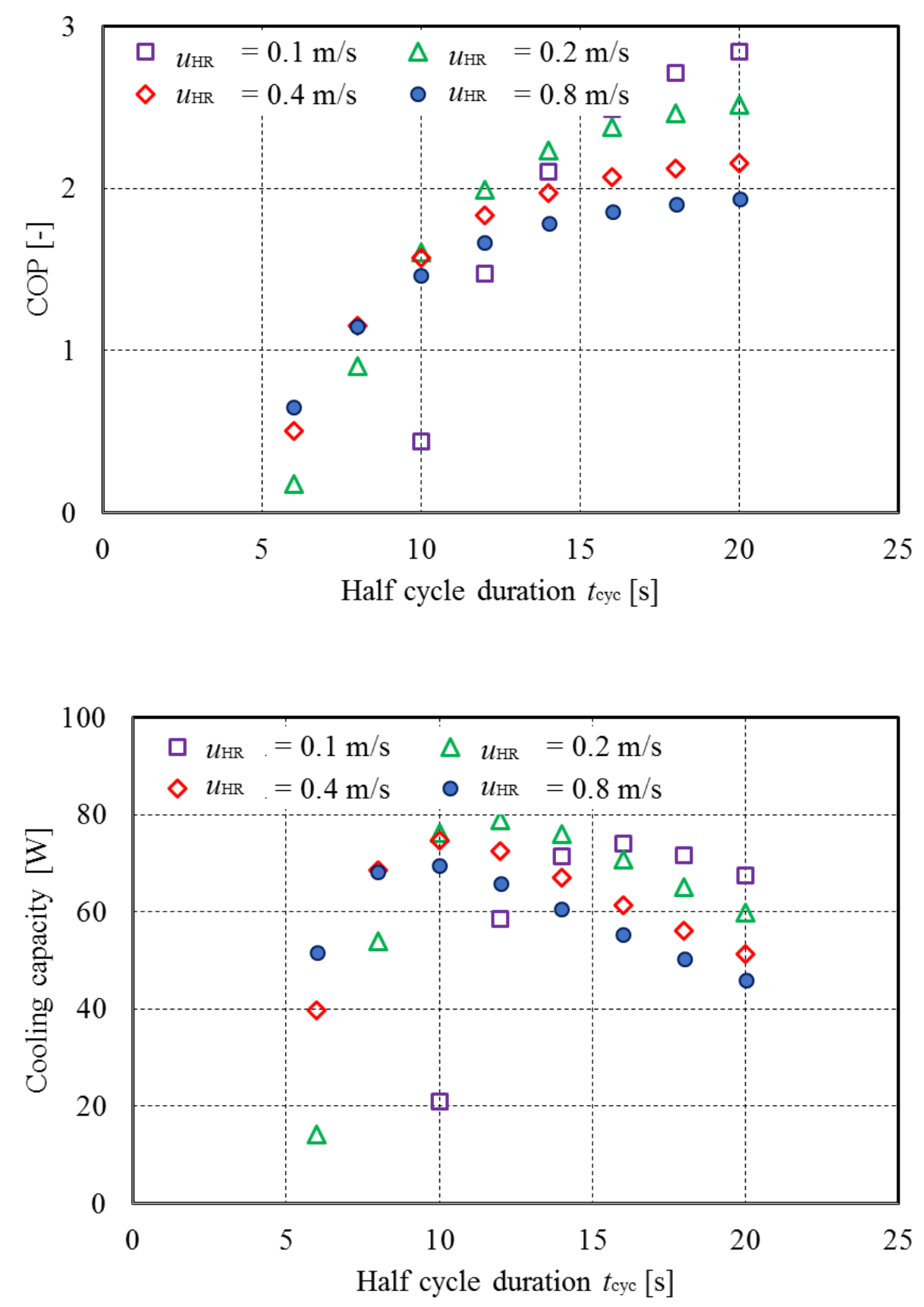

Figure 11: Model predicted COP and cooling capacity as a function of cycle duration (NiTi alloy, $\left.u_{\mathrm{HT}}=1.2 \mathrm{~m} / \mathrm{s}, \mathrm{L}=0.254 \mathrm{~m}, \mathrm{OD}=0.005 \mathrm{~m}, \mathrm{ID}=0.004 \mathrm{~m}, \mathrm{~N}=19, \Delta T_{\text {lift }}=10 \mathrm{~K}\right)$. 

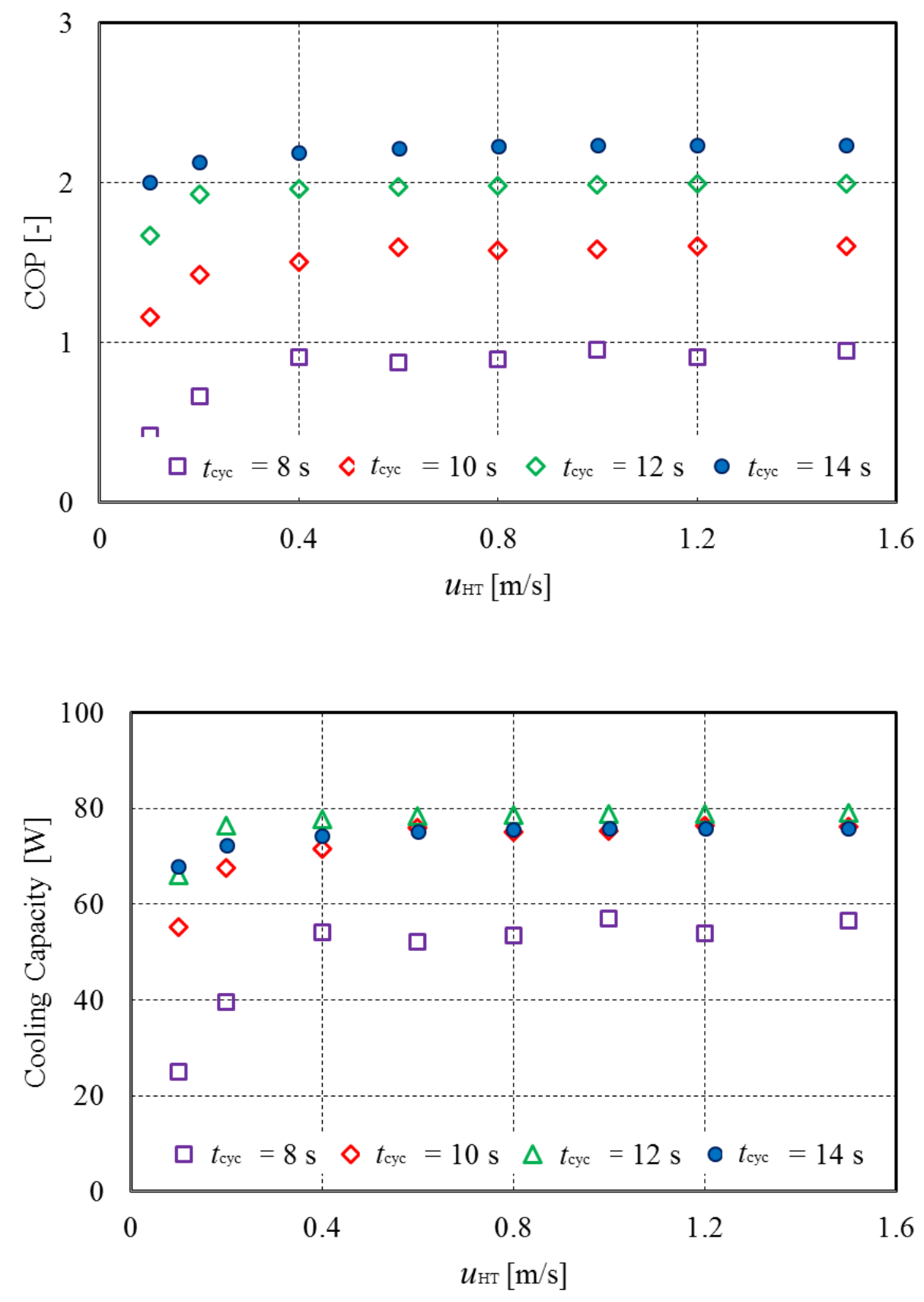

Figure 12: Model predicted COP and cooling capacity as a function of heat transfer flow rate $\left(\mathrm{NiTi}\right.$ alloy, $u_{\mathrm{HR}}=0.2 \mathrm{~m} / \mathrm{s}, \mathrm{L}=0.254 \mathrm{~m}, \mathrm{OD}=0.005 \mathrm{~m}, \mathrm{ID}=0.004 \mathrm{~m}, \mathrm{~N}=19, \Delta T_{\text {lift }}=10$ K). 

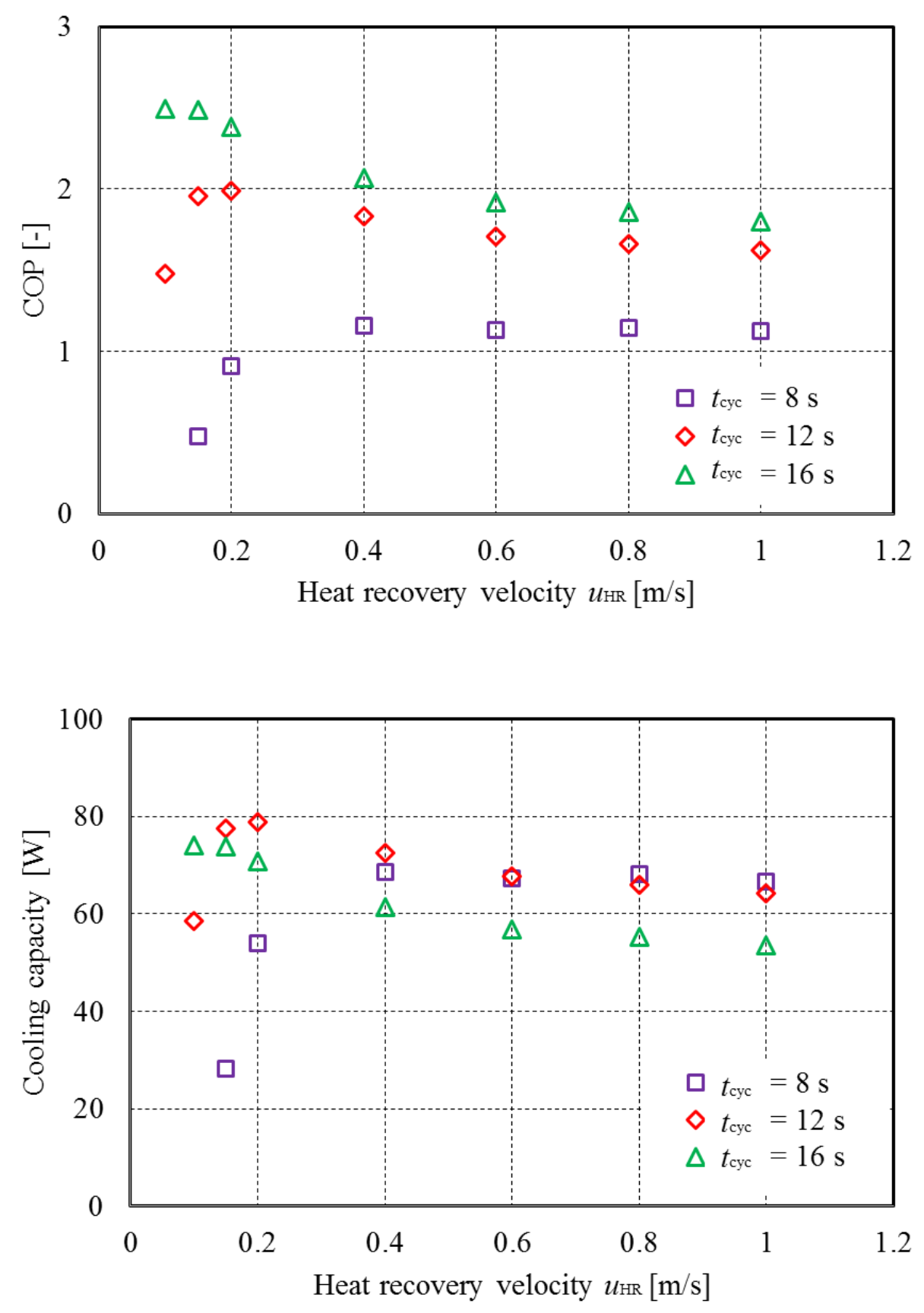

Figure 13: Model predicted COP and cooling capacity as a function of heat recovery flow rate $\left(\mathrm{NiTi}\right.$ alloy, $u_{\mathrm{HT}}=1.2 \mathrm{~m} / \mathrm{s}, \mathrm{L}=0.254 \mathrm{~m}, \mathrm{OD}=0.005 \mathrm{~m}, \mathrm{ID}=0.004 \mathrm{~m}, \mathrm{~N}=19, \Delta T_{\text {lift }}=10$ K). 


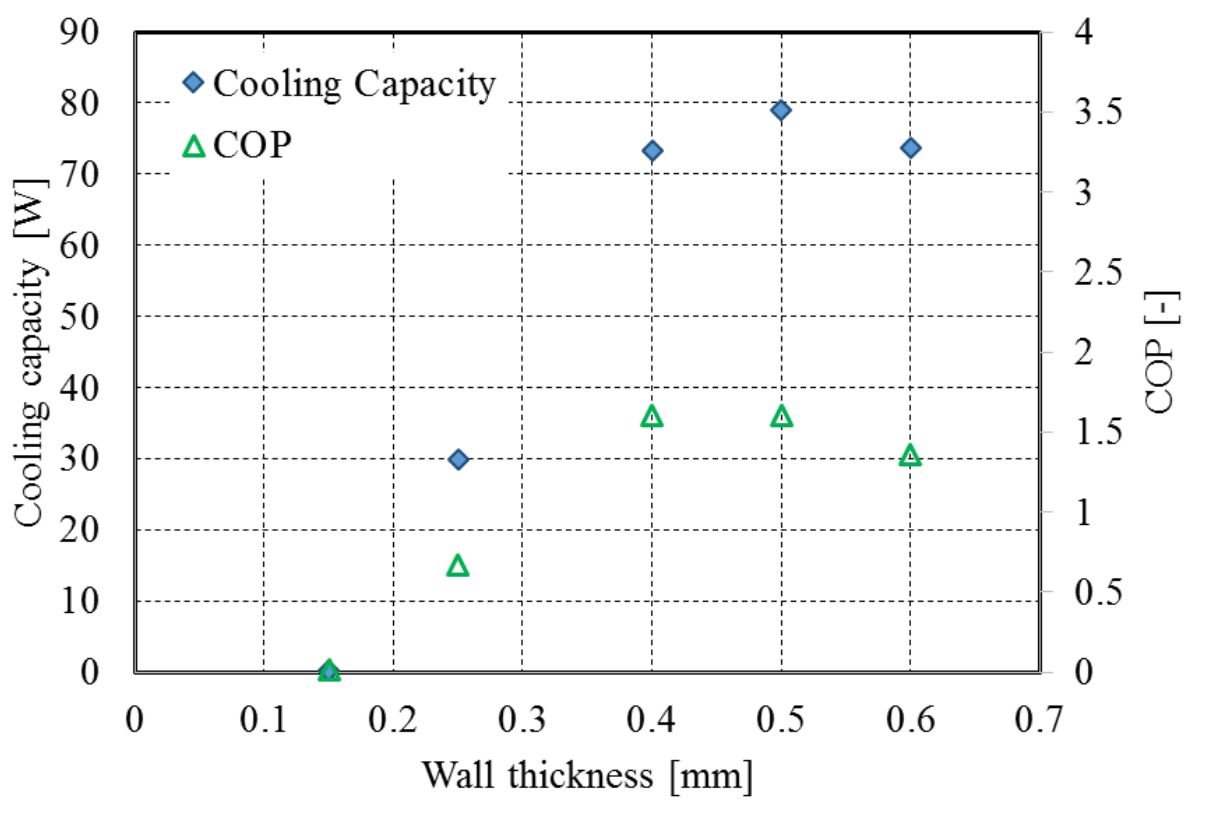

Figure 14: Effect of NiTi tube wall thickness on COP and system cooling capacity (NiTi alloy, $\left.u_{\mathrm{HT}}=1.2 \mathrm{~m} / \mathrm{s}, u_{\mathrm{HT}}=0.2 \mathrm{~m} / \mathrm{s}, \mathrm{L}=0.254 \mathrm{~m}, \mathrm{OD}=0.005 \mathrm{~m}, \Delta T_{\text {lift }}=10 \mathrm{~K}, \mathrm{~N}=13-59\right)$. 


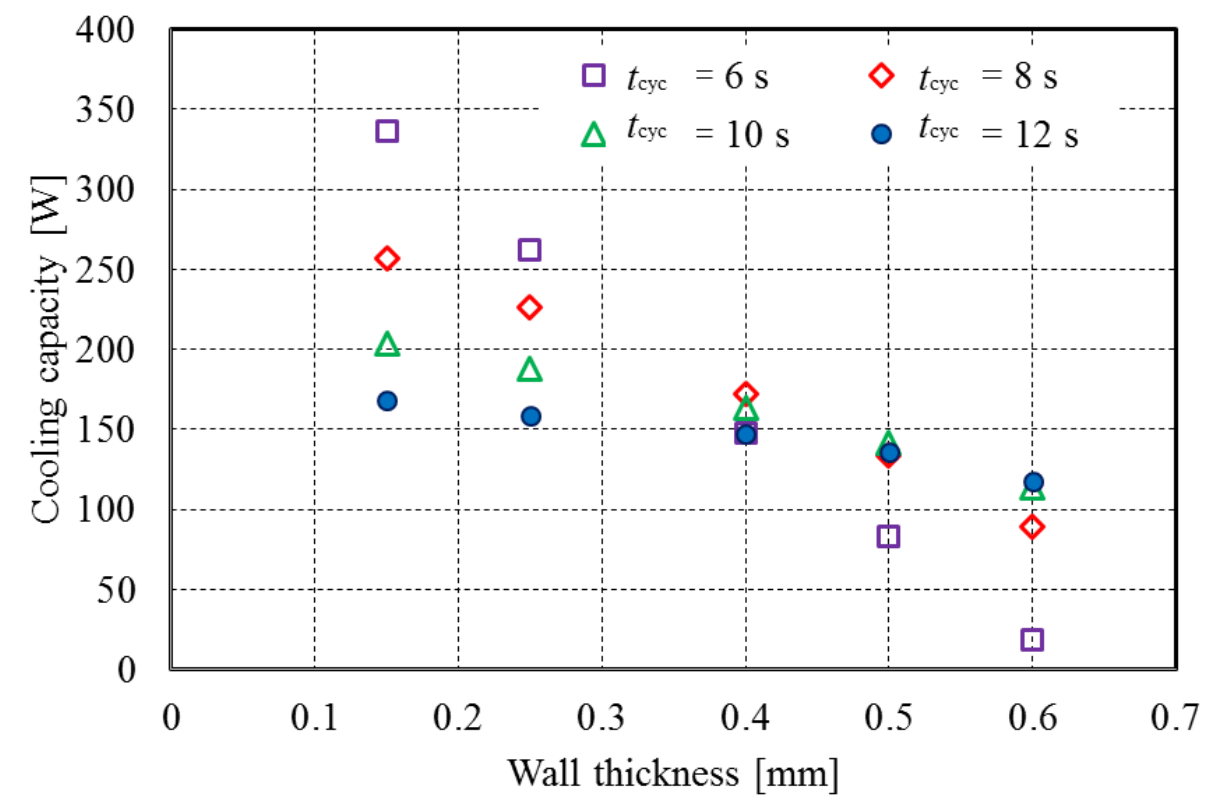

Figure 15: Illustration of NiTi bed's cooling capacity when varying NiTi tube wall thickness. (Note that the bed's cooling capacity is different from system cooling capacity since some cooling energy is dissipated along pipes) 


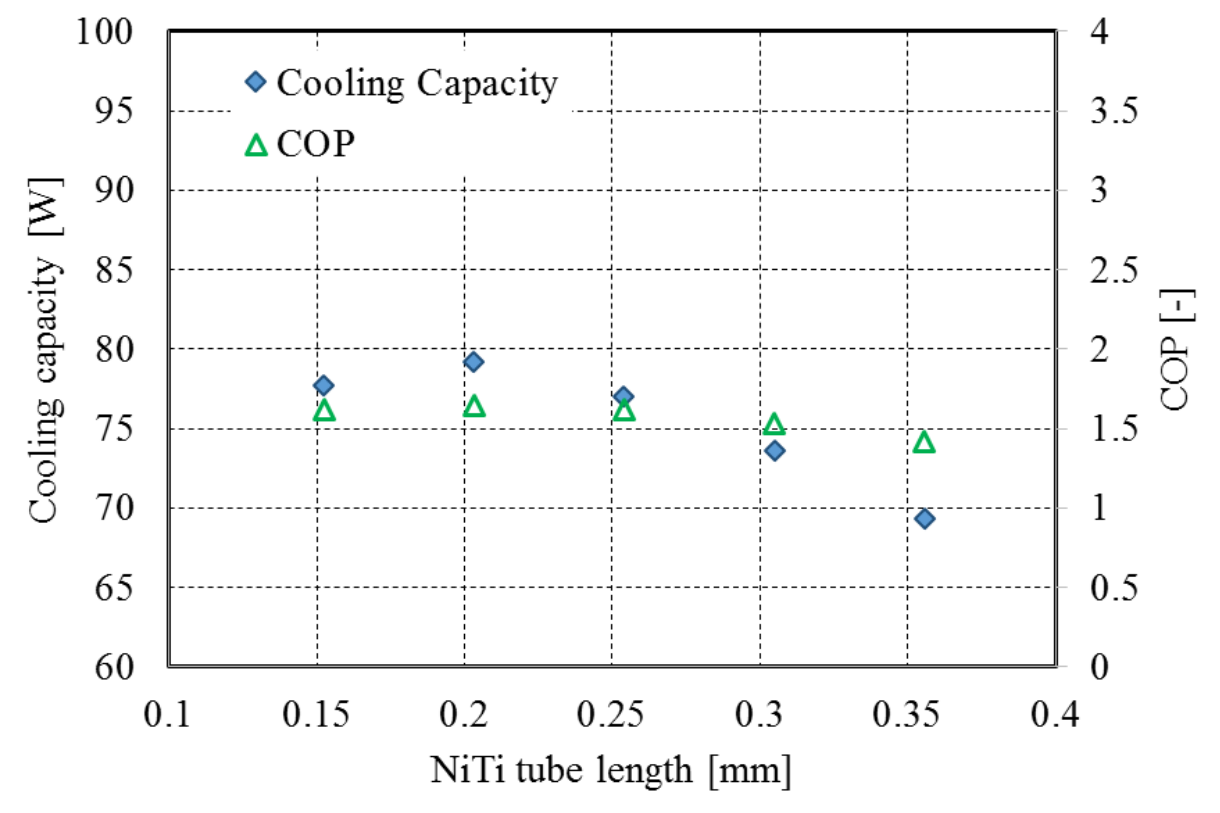

Figure 16: Effect of NiTi tube length on COP and cooling capacity (NiTi alloy, $u_{\mathrm{HT}}=1.2 \mathrm{~m} / \mathrm{s}$, $\left.u_{\mathrm{HT}}=0.2 \mathrm{~m} / \mathrm{s}, \mathrm{ID}=0.004 \mathrm{~m}, \mathrm{OD}=0.005 \mathrm{~m}, \Delta T_{\text {lift }}=10 \mathrm{~K}, \mathrm{~N}=14-32\right)$. 

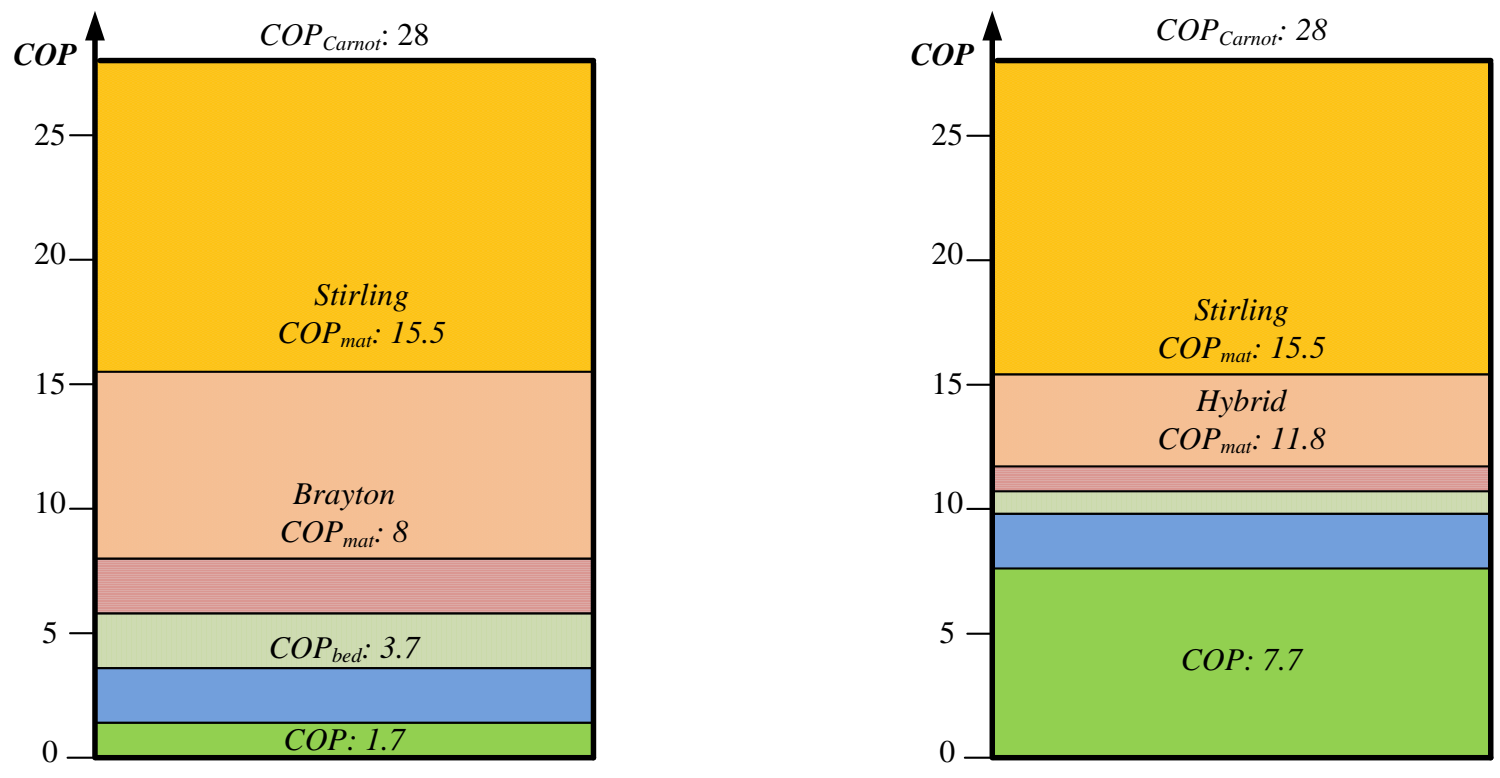

Losses contributions

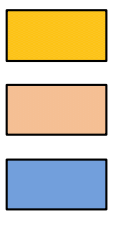

1. Irreversible Martensitic phase change losses (hysteresis)

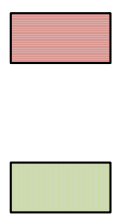

3. Mechanical losses due to motor efficiency $\eta_{\text {mot }}$ and work recovery efficiency $\eta_{\text {rec }}$

2. Adiabatic compression loss

5. Cyclic losses and pump work

4. Heat transfer losses for solid-state refrigerant only, due to effectiveness $\varepsilon$ and heat recovery efficiency $\eta_{\mathrm{HR}}$

(a) $\mathrm{COP}=1.7$ for a typical cycle studied

(b) $\mathrm{COP}=7.7$ for a cycle with $50 \%$

and corresponding losses

reduced losses expect pump work and

cyclic loss

Figure 17: Illustration of breakdown COP chart of the studied compressive thermoelastic

cooling system (NiTi alloy, operating on $10 \mathrm{~K}$ temperature lift from $15^{\circ} \mathrm{C}$ to $25^{\circ} \mathrm{C}$, with a set of typical operating parameters). 


\section{List of Figure Captions}

Figure 1: Illustration of martensitic phase change processes.

Figure 2: Illustration of a twin-crank SMA heat engine design using nitinol wires without any regenerator or heat recovery device (Shin et al., 1987).

Figure 3: Illustration of reverse Brayton cycle and its variation as a thermoelastic cooling cycle.

Figure 4: Illustration of reverse Stirling cycle and its variation as a thermoelastic cooling cycle.

Figure 5: Illustration of the temperature profiles of solid-state thermoelastic SMA beds during one cooling cycle.

Figure 6: Schematic of the heat transfer fluid loop used for the numerical model.

Figure 7: Analytical COP as a function of heat recovery efficiency.

Figure 8: Analytical COP and cooling capacity as a function of heat transfer effectiveness.

Figure 9: Analytical COP and cooling capacity as a function of temperature lift.

Figure 10: Temperature profiles predicted by the numerical model.

Figure 11: Model predicted COP and cooling capacity as a function of cycle duration.

Figure 12: Model predicted COP and cooling capacity as a function of heat transfer flow rate.

Figure 13: Model predicted COP and cooling capacity as a function of heat recovery flow rate.

Figure 14: Effect of NiTi tube wall thickness on COP and cooling capacity.

Figure 15: Illustration of NiTi bed's cooling capacity when varying NiTi tube wall thickness.

Figure 16: Effect of NiTi tube length on COP and cooling capacity. 
Figure 17: Illustration of breakdown COP chart of the studied compressive thermoelastic cooling system. 
Table 1: Physical properties and phase change parameters of some common SMA with giant elastocaloric effect. $(*)$

\begin{tabular}{|c|c|c|c|}
\hline Materials & NiTi & $\mathrm{CuZnAl}$ & CuAlNi \\
\hline Density $\left[\mathrm{kg} \cdot \mathrm{m}^{-3}\right]$ & $6400-6500(6500)$ & $7500-8000(7900)$ & $7100-7200(7150)$ \\
\hline$c_{\mathrm{p}}\left[\mathrm{J} \cdot \mathrm{kg}^{-1} \cdot \mathrm{K}^{-1}\right]$ & $470-620(550)$ & $390-400(400)$ & $373-480(440)$ \\
\hline $\begin{array}{l}\text { Conductivity } \\
{\left[\mathrm{W} \cdot \mathrm{m}^{-1} \cdot \mathrm{K}^{-1}\right]}\end{array}$ & 8.6-18 (18) & $84-120(120)$ & $30-75(75)$ \\
\hline$\Delta s\left[\mathrm{~J} \cdot \mathrm{kg}^{-1} \cdot \mathrm{K}^{-1}\right]$ & 42 & $19-26(20)$ & $20-30(20)$ \\
\hline$\Delta T_{\mathrm{ad}}[\mathrm{K}]$ & $22.9(300 \mathrm{~K})$ & $15.0(300 \mathrm{~K})$ & $13.6(300 \mathrm{~K})$ \\
\hline $\begin{array}{l}\text { Transformation } \\
\text { temperature }\left[{ }^{\circ} \mathrm{C}\right]\end{array}$ & $-200-200$ & $-200-150$ & $-200-200$ \\
\hline$A\left[\mathrm{~J} \cdot \mathrm{kg}^{-1}\right]$ & 120 & 155 & 280 \\
\hline$K[\mathrm{MPa}]$ & $1.72 \times 10^{4}$ & $3.10 \times 10^{4}$ & $4.90 \times 10^{3}$ \\
\hline$\Delta$ & 0.02 & 0.025 & 0.029 \\
\hline$w+$ (Brayton) $\left[\mathrm{J} \cdot \mathrm{g}^{-1}\right]$ & 5.64 & 1.58 & 3.02 \\
\hline$w$ - (Brayton) $\left[\mathrm{J} \cdot \mathrm{g}^{-1}\right]$ & 4.14 & 0.78 & 1.99 \\
\hline$w_{\text {net }}\left(\right.$ Brayton) $\left[\mathrm{J} \cdot \mathrm{g}^{-1}\right]$ & 1.50 & 0.80 & 1.03 \\
\hline$\gamma$ & 2.29 & 1.50 & 1.36 \\
\hline \multirow[t]{2}{*}{$C O P_{\text {mat }}$ (Brayton) } & 2.5 (Tensile) & 6.9 (Tensile) & 7.6 (Tensile) \\
\hline & 8.0 (Compressive) & 6.8 (Compressive) & 5.2 (Compressive) \\
\hline$C O P_{\text {mat }}$ & 3.4 (Tensile) & 11.9 (Tensile) & 11.9 (Tensile) \\
\hline (Stirling) & 15.5 (Compressive) & 11.4 (Compressive) & 7.2 (Compressive) \\
\hline \multirow[t]{9}{*}{ Data reference } & Cui et al., 2012 & Ziokolwski, 1993 & Friend and Hamilton, 1995 \\
\hline & Smith et al., 1993 & Otsuka and Wayman, 1998 & Rodriguez and Brown, 1980 \\
\hline & Otsuka and Wayman, & Bonnot et al., 2008 & Huang, 2002 \\
\hline & 1998 & Manosa et al., 1993 & Chen et al., 2009 \\
\hline & & Manosa et al., 2009 & Picornell et al., 2001 \\
\hline & & Sittner and Novak, 2000 & Picornell et al., 2004 \\
\hline & & Manosa et al., 2013 & \\
\hline & & Gall et al., 1998 & \\
\hline & & Lashley et al., 2007 & \\
\hline
\end{tabular}

\footnotetext{
* The numbers in bracket are specific numbers used for all calculation in this study.

NiTi: Ni 55 wt $\%$; CuZnAl: Cu 65 wt $\%$ - 70 wt $\%$, Al 13 wt $\%$ - 23 wt $\%$; CuAlNi: Al 12-15 wt $\%, \mathrm{Cu} 80$ wt $\%$ $-85 \mathrm{wt} \%$.

Also, $288 \mathrm{~K}$ to $298 \mathrm{~K}$ heat pump with $10 \mathrm{~K}$ temperature lift is used to evaluate the non-dimensional latent heat $\gamma$ and other temperature dependent parameters here in this table.
} 
Table 2: Valves and pumps sequence of the thermoelastic cooling system model.

\begin{tabular}{|c|c|c|c|c|c|c|}
\hline $\begin{array}{l}\text { Process in } \\
\text { Figure } 7\end{array}$ & $1 \rightarrow 2$ & $2 \rightarrow 3$ & $3 \rightarrow 4$ & $4 \rightarrow 5$ & $5 \rightarrow 6$ & $6 \rightarrow 1^{\prime}$ \\
\hline Description & $\begin{array}{l}\text { Adiabatic } \\
\text { phase } \\
\text { change }\end{array}$ & $\begin{array}{l}\text { Heat } \\
\text { transfer }\end{array}$ & $\begin{array}{l}\text { Heat } \\
\text { recovery }\end{array}$ & $\begin{array}{l}\text { Adiabatic } \\
\text { phase } \\
\text { change }\end{array}$ & $\begin{array}{l}\text { Heat } \\
\text { transfer }\end{array}$ & $\begin{array}{l}\text { Heat } \\
\text { recovery }\end{array}$ \\
\hline V1 & $\mathrm{X}$ & $\mathrm{O}$ & $X$ & $\mathrm{X}$ & $X$ & $X$ \\
\hline V2 & $X$ & $\mathrm{X}$ & $X$ & $\mathrm{X}$ & $\mathrm{O}$ & $X$ \\
\hline V3 & $X$ & $\mathrm{O}$ & $X$ & $X$ & $X$ & $\mathrm{X}$ \\
\hline V4 & $X$ & $X$ & $X$ & $X$ & $\mathrm{O}$ & $X$ \\
\hline V5 & $\mathrm{X}$ & $X$ & $X$ & $\mathrm{X}$ & $\mathrm{O}$ & $X$ \\
\hline V6 & $X$ & $\mathrm{O}$ & $X$ & $X$ & $X$ & $X$ \\
\hline V7 & $X$ & $\mathrm{X}$ & $X$ & $\mathrm{X}$ & $\mathrm{O}$ & $X$ \\
\hline V8 & $\mathrm{X}$ & $\mathrm{O}$ & $X$ & $\mathrm{X}$ & $X$ & $X$ \\
\hline HRV & $X$ & $X$ & $\mathrm{O}$ & $\mathrm{X}$ & $X$ & $\mathrm{O}$ \\
\hline Pump1 & $X$ & $\mathrm{O}$ & $X$ & $X$ & $\mathrm{O}$ & $X$ \\
\hline Pump2 & $\mathrm{X}$ & $\mathrm{O}$ & $\mathrm{X}$ & $X$ & $\mathrm{O}$ & $\mathrm{X}$ \\
\hline Pump3 & $\mathrm{X}$ & $X$ & $\mathrm{O}$ & $X$ & $X$ & $\mathrm{O}$ \\
\hline$\dot{\bar{e}}$ & $1 / \Delta t_{+}$ & 0 & 0 & $1 / \Delta t_{+}$ & 0 & 0 \\
\hline
\end{tabular}

Note: "X" is close/off, "O" is open/on. 